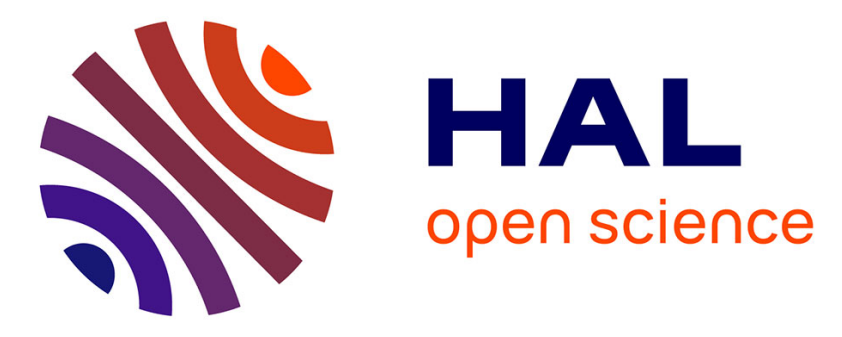

\title{
Vibrational modes of water predict spectral niches for photosynthesis in lakes and oceans
}

Tadzio Holtrop, Jef Huisman, Maayke Stomp, Levi Biersteker, Jeroen Aerts, Théophile Grébert, Frédéric Partensky, Laurence Garczarek, Hendrik Jan van Der Woerd, Hendrik Jan van Der Woerd

\section{To cite this version:}

Tadzio Holtrop, Jef Huisman, Maayke Stomp, Levi Biersteker, Jeroen Aerts, et al.. Vibrational modes of water predict spectral niches for photosynthesis in lakes and oceans. Nature Ecology \& Evolution, 2021, 10.1038/s41559-020-01330-x . hal-02999397

\section{HAL Id: hal-02999397 https://hal.science/hal-02999397}

Submitted on 10 Nov 2020

HAL is a multi-disciplinary open access archive for the deposit and dissemination of scientific research documents, whether they are published or not. The documents may come from teaching and research institutions in France or abroad, or from public or private research centers.
L'archive ouverte pluridisciplinaire HAL, est destinée au dépôt et à la diffusion de documents scientifiques de niveau recherche, publiés ou non, émanant des établissements d'enseignement et de recherche français ou étrangers, des laboratoires publics ou privés. 


\section{Vibrational modes of water predict spectral niches for photosynthesis in lakes and oceans}

Short title: Spectral niches in lakes and oceans

One-sentence summary: Large-scale biogeographical distribution of cyanobacterial pigments is predicted from the molecular vibrations of $\mathrm{H}_{2} \mathrm{O}$

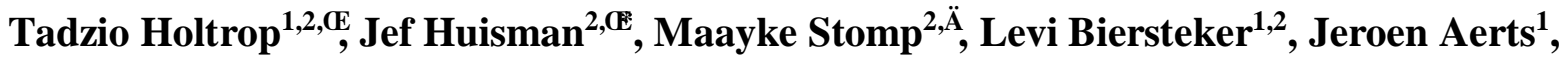
Théophile Grébert ${ }^{3}$, Frédéric Partensky ${ }^{3}$, Laurence Garczarek ${ }^{3}$, Hendrik Jan van der Woerd ${ }^{1}$

1. Institute for Environmental Studies (IVM), Department of Water \& Climate Risk, VU University Amsterdam, De Boelelaan 1087, 1081 HV Amsterdam, The Netherlands

2. Department of Freshwater and Marine Ecology (FAME), Institute for Biodiversity and Ecosystem Dynamics, University of Amsterdam, P.O. Box 94240, 1090 GE Amsterdam, The Netherlands

3. Sorbonne Université, CNRS, Station Biologique, UMR 7144 Adaptation and Diversity in the Marine Environment, 29680 Roscoff, France

ÿ These authors contributed equally: Tadzio Holtrop, Jef Huisman.

ÀDeceased: Maayke Stomp, August 4, 2017

*Corresponding author: j.huisman@uva.nl

\section{Abstract}

Stretching and bending vibrations of water molecules absorb photons of specific wavelengths, a phenomenon that constrains light energy available for aquatic photosynthesis. Previous work suggested that these absorption properties of water create a series of spectral niches, but the theory was still too simplified to enable prediction of the spectral niches in real aquatic ecosystems. Here, we show with a stateof-the-art radiative transfer model that the vibrational modes of the water molecule delineate five spectral niches, in the violet, blue, green, orange and red part of the spectrum. These five niches are effectively captured by chlorophylls and phycobilin pigments of cyanobacteria and their eukaryotic descendants. Global distributions of the 
spectral niches are predicted by satellite remote sensing, and validated with observed large-scale distribution patterns of cyanobacterial pigment types. Our findings provide an elegant explanation for the biogeographical distributions of photosynthetic pigments across the lakes and oceans of our planet.

An intriguing question about the evolution of life on our planet is why photosynthetic organisms have evolved a whole suite of different pigments. Why is there not a single photosynthetic pigment that is optimal under all light conditions? Already in the late $19^{\text {th }}$ century, Engelmann demonstrated that chlorophyll of green algae absorbs light only in the blue and red parts of the spectrum ${ }^{1}$. One year later, he showed that cyanobacteria are particularly effective in the exploitation of orange light ${ }^{2}$. A major consequence of this preference for specific colors of light is that phototrophs can occupy different ápectral nichesôin the underwater radiation field ${ }^{3,4}$. Hence, changes in water color may shift the competitive interactions between phytoplankton species that differ in pigment composition and thereby exploit different parts of the light spectrum ${ }^{5 i} 10$.

Underwater irradiance spectra are generated by wavelength-dependent absorption and scattering of light by water, colored dissolved organic matter (CDOM), non-algal particles (NAP) such as minerals and detritus, and phytoplankton ${ }^{11,12}$. Pure water absorbs strongly in the red and infra-red, whereas it scatters photons particularly in the violet and blue part of the spectrum (Fig. 1). CDOM absorbs strongly in the violet and blue part of the spectrum, whereas the contribution of CDOM to scattering is negligible ${ }^{11,12}$ (Extended Data Fig. 1). Absorption properties of NAP and phytoplankton vary depending on their composition, and both NAP and phytoplankton can have a major effect on light scattering ${ }^{13}$.

One might expect to find a smooth continuum of different underwater light spectra across the aquatic ecosystems of our planet, from violet-blue colors in the clearest ocean waters ${ }^{14}$ to dark red-brown colors in humic lakes with high CDOM concentrations. However, Stomp and colleagues ${ }^{4}$ discovered that the absorption properties of water and its optical constituents create a series of distinct spectral niches in aquatic ecosystems. At the heart of this finding is the behavior of the water molecule itself. Water molecules absorb photons more efficiently at specific wavelengths, where the energy of these photons enables molecular vibrations of the covalent $\mathrm{O}-\mathrm{H}$ bonds in $\mathrm{H}_{2} \mathrm{O}$. Water molecules display three fundamental vibrational modes: symmetric stretching, asymmetric stretching and bending (Fig. 1a). The fundamental vibrational modes, and combinations thereof (known as harmonics), have created a series of shoulders in the visible and infrared part of the absorption spectrum of water (Fig. 1b). The $4^{\text {th }}, 5^{\text {th }}, 6^{\text {th }}, 7^{\text {th }}$ and $8^{\text {th }}$ harmonics of the stretching 
vibrations can be identified at 742, 605, 514, 449 and $401 \mathrm{~nm}$, respectively ${ }^{15 i}{ }^{18}$. More subtle shoulders exist between the $4^{\text {th }}$ and $5^{\text {th }}$ harmonic at $662 \mathrm{~nm}$ and between the $5^{\text {th }}$ and $6^{\text {th }}$ harmonic at $550 \mathrm{~nm}$, which correspond to combinations of stretching and bending vibrations and are referred to as the 4.1 and 5.1 subharmonics, respectively.

Because light is attenuated exponentially with depth, small local maxima in the total absorption spectrum of water and its optical constituents produce deep valleys of minimal energy availability in underwater light spectra. Stomp et al. ${ }^{4}$ found that the spectral valleys generated by the shoulders in the absorption spectrum of pure water demarcate a series of distinct spectral niches in waters with different CDOM concentrations. Moreover, they showed that phototrophic microorganisms have tuned the absorption spectra of their pigments to these different spectral niches ${ }^{4}$. More specifically, peaks in the absorption spectra of photosynthetic bacteria and algae coincide with areas of maximum energy availability and skip the spectral valleys generated by the vibrational harmonics of the water molecule.

The work of Stomp and colleagues was merely of a conceptual nature. It assumed that light absorption is governed by Lambert-Beerô law and ignored scattering of light. Furthermore, it did not show whether the above principles can be used to predict, for instance, the biogeographical distributions of phytoplankton species. Hence, to what extent these conceptual insights can be applied to real ecosystems is still unclear. However, improvements in water purification techniques and laboratory instrumentation have led to better estimates of the absorption spectrum of pure water at wavelengths $<550 \mathrm{~nm}^{18}$. Comprehensive models make it possible to accurately calculate underwater irradiance fields from inherent optical properties using radiative transfer equations ${ }^{11,19}$. Substantial advances have been made to estimate inherent optical properties of different waterbodies by satellite remote sensing ${ }^{20,21}$. Furthermore, new genetic markers have enabled quantification of the global oceanic distributions of cyanobacterial pigment types ${ }^{9,22}$.

Here, we combine the earlier conceptual insights ${ }^{4}$ with these technological advances to obtain more accurate predictions of the spectral niches and to predict the global distributions of these spectral niches across the lakes and oceans of our planet. For this purpose, we replace Lambert-Beerôs equation by a state-of-the-art radiative transfer model ${ }^{19}$ that includes elastic and inelastic scattering of light to obtain a more realistic description of the spectral radiance field. Furthermore, we include new data on the absorption spectrum of pure water ${ }^{18}$ to achieve a more accurate description of light absorption at $<550 \mathrm{~nm}$. The spectral niches predicted by this radiative transfer model show a striking match with the absorption spectra of cyanobacteria, the numerically most abundant group of photosynthetic organisms in aquatic ecosystems and evolutionary ancestors of the chloroplasts of eukaryotic algae and 
plants. We combine the model with spectral signatures obtained by satellite remote sensing to map the global distributions of the spectral niches. Finally, we synthesize all these results by comparing the predicted global distributions of the spectral niches with the observed largescale biogeographical distributions of cyanobacterial pigment types.

\section{Results}

\section{Underwater light spectra}

Our study aims at investigating which spectral niches in the range of photosynthetically active radiation (PAR, 400-700 $\mathrm{nm}$ ) are available for phytoplankton photosynthesis. Therefore, we model underwater irradiance spectra generated by water, CDOM and NAP but without phytoplankton, to derive the underwater spectra created by the abiotic environment. These spectral niches serve as templates for subsequent phytoplankton photosynthesis.

We first calculate absorption spectra in waters with different CDOM concentrations but without NAP (Fig. 2a). In the clearest ocean waters with very low CDOM concentrations, the total absorption spectrum resembles that of pure water, and all five (sub)-harmonics in the PAR range are evident in the absorption spectrum. With increasing CDOM concentration, absorption by CDOM starts to dominate the absorption spectrum, first only at shorter wavelengths and at higher CDOM concentrations also at longer wavelengths.

These absorption spectra are used to simulate the spectral distribution of scalar irradiance as function of depth for waters with different CDOM concentrations. The results are illustrated by 100 underwater spectra at three different photic depths receiving $10 \%, 3 \%$ and $1 \%$ of the surface irradiance, respectively (Fig. 2b-d). At very low CDOM concentrations typical of the oligotrophic ocean, the underwater spectra are mostly dominated by violet and blue light (400-500 nm). At very high CDOM concentrations, underwater spectra are dominated by orange and red light (600-700 nm), because most blue and green photons have been absorbed by CDOM in the upper few centimeters of the water column.

Together, these 100 spectra form a landscape of peaks and valleys. The peaks and valleys become more pronounced at greater optical depth because of the exponential nature of light attenuation (Fig. 2b-d). Deep valleys in this spectral landscape coincide with the $5^{\text {th }}$, $6^{\text {th }}, 7^{\text {th }}$ and $8^{\text {th }}$ harmonics of the stretching modes of the water molecule. The 4.1 and 5.1 subharmonics at 662 and $550 \mathrm{~nm}$ have a smaller imprint on underwater light spectra (Fig. 2b-d).

For comparison, we also calculated underwater irradiance spectra for a ónull modelôin which the absorption spectrum of water was replaced by a smooth absorption spectrum that ignores the vibrational modes of the water molecule. In this case, the radiative transfer model predicts a rather uniform spectral landscape without pronounced peaks and valleys (Extended 
Data Fig. 2). This result demonstrates that the vibrational modes of the water molecule are indeed responsible for the deep valleys in the underwater irradiance spectra.

The incident solar spectrum also contains several conspicuous dips in the PAR range, most notably Fraunhofer line b $(517 \mathrm{~nm})$ and line $\mathrm{G}(431 \mathrm{~nm})$ and the alpha line $(656 \mathrm{~nm})$ and beta line $(486 \mathrm{~nm})$ of the Balmer series. All four lines are visible as small indents in the underwater light spectra. The alpha line is close to the 4.1 subharmonic, and their joint effect creates a small but distinct area of minimal energy availability in the 656-662 nm range (Fig. 2b-d). Similarly, Fraunhofer line b overlaps with the $6^{\text {th }}$ harmonic of the vibration of the water molecule (514-517 nm). Fraunhofer line $\mathrm{G}$ and the beta line do not coincide with the harmonics and only cause a minor depression in underwater spectra. Signatures of the chemical composition of the Earthôs atmosphere are also visible in the underwater light field (e.g. the $686 \mathrm{~nm}$ line complex of oxygen). In total, however, our results show that the harmonics of the water molecule have a much more pronounced effect on underwater light spectra than absorption lines in the solar spectrum and Earthô atmosphere (Fig. 2b-d).

Next, we added NAP to the model to study effects of particle scattering across a wide range of NAP concentrations $\left(0.04-320 \mathrm{mg} / \mathrm{m}^{3}\right)$. Both CDOM and NAP absorb strongly at short wavelengths, but scattering by CDOM is negligible whereas scattering by NAP is substantial along the entire spectral range (Extended Data Fig. 1). This difference in optical properties introduces slight differences between underwater light spectra of CDOMdominated and NAP-dominated waters, but the pronounced peaks and valleys shaped by the harmonics of the water molecule remain evident throughout (Supplementary Video).

\section{Five spectral niches}

Large peaks in the spectral landscape (Fig. 2b-d) can be interpreted as distinct ópectral nichesôthat are available for aquatic photosynthesis ${ }^{4}$. The spectral niches are demarcated by deep valleys at the $8^{\text {th }}, 7^{\text {th }}, 6^{\text {th }}$ and $5^{\text {th }}$ harmonics of $\mathrm{H}_{2} \mathrm{O} \hat{\text { Q }}$ molecular vibrations at 401,449 , $514,605 \mathrm{~nm}$, respectively. Furthermore, the proximity of the 4.1 subharmonic and the alpha line of the Balmer series generates a small energy minimum at 656-662 nm that might also constitute a subtle boundary between two spectral niches. By contrast, the 5.1 subharmonic leaves only a marginal depression in underwater light spectra (Fig. 2b-d), which is unlikely to have induced spectral niche differentiation. Hence, a total of five spectral niches can be distinguished in the PAR range. We will refer to these five niches by their corresponding colors, as the violet, blue, green, orange and red niche, respectively (Table 1).

Although essentially all wavelengths of the incident solar spectrum are available near the water surface, underwater irradiance spectra narrow down with increasing depth (Fig. 2b- 
d). Our results indicate that harmonics of the water molecule become visible as spectral valleys in underwater irradiance spectra when total PAR (integrated over 400-700 nm) has been attenuated to Ò $0 \%$ of the surface irradiance (Fig. 2b). The $10 \%$ light level is located midway between the surface and the euphotic depth at $1 \%$ of the surface irradiance. Hence, the spectral niches can be clearly discerned in the lower half of the euphotic zone.

\section{Cyanobacterial pigments}

The five spectral niches are effectively captured by photosynthetic pigments of cyanobacteria. The most abundant photosynthetic organism in the oceans, Prochlorococcus, uses divinyl chlorophyll (dChl) $a$ and $b$ as its major photosynthetic pigments ${ }^{23-25}$. dChl $a$ has a large in vivo absorption peak at $\sim 443 \mathrm{~nm}$ and a smaller one at $\sim 673 \mathrm{~nm}$, which capture the violet niche between the $8^{\text {th }}$ and $7^{\text {th }}$ harmonic and the red niche at wavelengths above the 4.1 harmonic, respectively (Fig. 3a; Table 1). dChl $b$ has a large in vivo absorption peak at 473 $\mathrm{nm}$ and a smaller one at $\sim 650 \mathrm{~nm}$ that capture the blue niche and orange niche, respectively.

Contrary to Prochlorococcus, most other cyanobacteria use large light-harvesting antennae called phycobilisomes ${ }^{26-28}$. Phycobilisomes consist of an allophycocyanin core and stacked rods of phycocyanin and/or phycoerythrin carrying accessory pigments called phycobilins. The phycobilin composition differs between strains, producing cells in a wide palette of colors ${ }^{7,27}$. Phycoerythrin carries the pigments phycourobilin (PUB) and phycoerythrobilin (PEB) with absorption peaks at $495 \mathrm{~nm}$ and 550-570 nm, respectively (Fig. 3b,c). Phycocyanin binds phycocyanobilin (PCB) with an absorption peak at $630 \mathrm{~nm}$ (Fig. $3 \mathrm{~d})$. Hence, PUB captures the blue niche between the $7^{\text {th }}$ and $6^{\text {th }}$ harmonic, PEB captures the green niche between the $6^{\text {th }}$ and $5^{\text {th }}$ harmonic, and PCB occupies the orange niche between the $5^{\text {th }}$ harmonic and 4.1 subharmonic (Fig. 3b-d; Table 1).

Some cyanobacterial strains can dynamically adjust their phycobilin composition by a process known as chromatic acclimation ${ }^{29}$. These chromatic acclimators alter their PUB:PEB ratio in response to changes in blue and green light ${ }^{9,30}$, or their PEB:PCB ratio in response to changes in green and orange light ${ }^{31,32}$ (Extended Data Fig. 3).

In addition, phycobilisome-containing cyanobacteria use Chl $a$ to absorb violet light of $\sim 440 \mathrm{~nm}$ and red light of $\sim 680 \mathrm{~nm}$ (Fig. 3b-d). However, they tend to have a much lower photosynthetic efficiency in light colors absorbed only by Chl $a$ than in light colors absorbed by their phycobilins ${ }^{10,33}$.

Accordingly, Prochlorococcus is specialized to life in the violet and blue niche, whereas phycobilisome-containing cyanobacteria such as Synechococcus are specialized on the blue, green or orange niche depending on their phycobilin composition. 


\section{Global distributions of spectral niches}

Global distributions of the five spectral niches were estimated by satellite remote sensing (Fig. 4). We used combined absorption by dissolved (CDOM) and detrital matter (NAP), measured from surface layers of lakes and oceans by the European Space Agency, as input for the radiative transfer model to predict the relative availability of the spectral niches at the euphotic depth (see Methods for details). The results show that the violet niche dominates in oligotrophic subtropical ocean gyres (Fig. 4a). The blue niche dominates in the temperate open ocean, equatorial upwelling areas, Mediterranean Sea, Black Sea, and oligotrophic lakes such as Lake Malawi and Lake Tanganyika (Fig. 4b). The green niche dominates in productive shallow seas, coastal upwelling areas, Baltic Sea, Caspian Sea, and mesoeutrophic lakes such as Lake Erie and Lake Victoria (Fig. 4c,d). The orange and red niche dominate in eutrophic and hypertrophic inland waters and estuaries with high concentrations of dissolved and detrital matter, as illustrated by the spatial gradient in Chesapeake Bay and the turbid waters of Pamlico Sound along the East coast of the USA (Fig. 4e,f). This prediction of a gradual shift in spectral niche composition along the trophic gradient is consistent with measured irradiance spectra from the clearest oceans to hypertrophic lakes (Extended Data Fig. 4).

\section{Biogeographical distribution of cyanobacteria}

Can the geographical distributions of the spectral niches (Fig. 4) explain the biogeographical distributions of the major cyanobacterial pigment types (Fig. 3)? To address this question, we use data on relative abundances of cyanobacterial pigment types collected from surface waters of 54 marine stations ${ }^{9,22}, 9$ stations in the brackish Baltic Sea ${ }^{7}$ and 59 lake stations ${ }^{5 i 7}$ (Fig. 5a). At each sampling station, the relative availability of the spectral niches was calculated from absorption by dissolved and detrital matter (Extended Data Fig. 5). Absorption by dissolved and detrital matter was retrieved from satellite remote sensing for the marine stations, whereas it was measured in water samples for the Baltic Sea and lake stations ${ }^{7}$.

The dChl $a$ and dChl $b$ pigments of Prochlorococcus capture the violet and blue niche (Fig. 3a). The violet niche dominates in subtropical ocean gyres (Fig. 4a), and Prochlorococcus is indeed by far the most abundant cyanobacterium in these transparent hyperoligotrophic waters (Fig. 5a). More specifically, our analysis shows that co-occurrence of the violet and blue niche explains $87 \%$ of the variation in the relative abundance of 
Prochlorococcus (Pearson correlation between observed and predicted values: $\mathrm{R}^{2}=0.87, \mathrm{n}=$ 122, $\mathrm{P}<0.001$; Fig. 5b).

PUB-rich Synechococcus are typical blue light specialists (Fig. 3b). They were found in waters with relatively low absorption by dissolved and detrital matter, in the range $0.005<$ $a_{\mathrm{dg}}(443)<0.1$, which is in good agreement with the predominance of the blue niche in these waters (Fig. 4b, Fig. 5). For example, the blue niche dominates in equatorial upwelling areas and the Mediterranean Sea (Fig. 4b), where PUB-rich Synechococcus reach high relative abundances (Fig. 5a). The blue niche is also widespread in temperate open ocean water, where PUB-rich Synechococcus can also be found. Quantitatively, the blue spectral niche explains $21 \%$ of the variation in relative abundance of PUB-rich Synechococcus across the globe $\left(\mathrm{R}^{2}=0.21, \mathrm{n}=122, \mathrm{P}<0.001\right.$; Fig. $\left.5 b\right)$.

Synechococcus cells capable of chromatic acclimation of their PUB:PEB ratio reach high relative abundances at several sites of the North Atlantic Ocean (Fig. 5a). Interestingly, measured underwater light spectra of the North Atlantic consist of one irradiance peak in the blue and another peak in the green spectral niche (Extended Data Fig. 4), matching the absorption peaks of PUB and PEB. In quantitative terms, co-occurrence of the blue and green niche explains only $19 \%$ of the variation in relative abundance of the PUB:PEB acclimators $\left(\mathrm{R}^{2}=0.19, \mathrm{n}=122, \mathrm{P}<0.001\right.$; Fig. $\left.5 \mathrm{~b}\right)$, indicating that accurate prediction of the abundances of chromatic acclimators is challenging. Moreover, we lack data in the range of $0.08<$ $a_{\mathrm{dg}}(443)<0.4$, where chromatic acclimators are predicted to be most abundant. Additional samples from marine continental shelves and large oligotrophic lakes (e.g., Lake Superior, Lake Baikal) might fill this gap. Qualitatively, however, the presence of PUB:PEB acclimators in the range $0.015<a_{\mathrm{dg}}(443)<0.08$ is well in line with the co-occurrence of the blue and green niche in these waters (Fig. 5b).

Synechococcus spp. with constitutively high PEB contents are green-light specialists. Some PEB-rich Synechococcus contain both PUB and PEB but with a low PUB:PEB ratio $^{27,34}$ (РT3a, brown line in Fig. 3c). They reach their highest abundance in productive coastal waters such as the Peruvian and Namibian upwelling areas (Fig. 5a), which are marine waters in which green light prevails (Fig. 4c). Other PEB-rich Synechococcus lack PUB and exhibit a slightly red-shifted PEB peak (PT2, magenta line in Fig. 3c). They are commonly found in the Baltic Sea and mesotrophic lakes ${ }^{5 i 7,35,36}$ (Fig. 5a; Extended Data Fig. 6), where green wavelengths also dominate the underwater light spectrum (Fig. 4c). The green niche explains $77 \%$ of the variation in relative abundance of PEB-rich Synechococcus $\left(R^{2}=0.77, n=122, P<0.001\right.$; Fig. 5b). 
Finally, PCB-rich cyanobacteria reach high abundances in eutrophic and hypertrophic lakes and estuaries ${ }^{5 i 7,36-38}$ (Extended Data Fig. 6), in agreement with the orange and red wavelengths that often dominate these turbid waters ${ }^{7,10}$. An example is provided by Lake á Joppe in The Netherlands, a hypertrophic lake in which the orange niche prevails (Extended Data Fig. 4), and which is frequently covered by potentially toxic blooms of the PCB-rich cyanobacterium Microcystis $^{39}$. The orange niche explains $69 \%$ of the global variation in relative abundance of PCB-rich cyanobacteria $\left(\mathrm{R}^{2}=0.69, \mathrm{n}=122, \mathrm{P}<0.001\right.$; Fig. 5b).

\section{Discussion}

The molecular vibrations of $\mathrm{H}_{2} \mathrm{O}$ left their signature in the absorption spectra of the cyanobacterial pigments on our planet. Although this intriguing phenomenon was discovered by Stomp et al. ${ }^{4}$, we extended their findings in important ways. Implementation of more accurate absorption data by water below $550 \mathrm{~nm}^{18}$ improved the distinction between the violet and blue niche separated by the $7^{\text {th }}$ harmonics, and shows that (d)Chl $a$ captures the violet niche whereas (d)Chl $b$ captures the blue niche (Fig. 3a). Furthermore, Stomp et al. ${ }^{4}$ (p. 279) incorrectly argued that PUB and PEB both occupy the spectral niche between the $6^{\text {th }}$ and $5^{\text {th }}$ harmonics. Instead, our results show that PUB captures the blue niche between the $7^{\text {th }}$ and $6^{\text {th }}$ harmonics, whereas PEB captures the green niche between the $6^{\text {th }}$ and $5^{\text {th }}$ harmonics (Fig. $3 b, c)$. Finally, incorporation of the 4.1 subharmonic separates the orange niche captured by (d)Chl $b$ and PCB and the red niche captured by (d)Chl $a$ (Fig. 3a,d). Hence, our results demonstrate that five spectral niches can be distinguished in the PAR range, delineated by the $8^{\text {th }}, 7^{\text {th }}, 6^{\text {th }}, 5^{\text {th }}$ and 4.1 (sub)harmonics of the molecular vibrations of $\mathrm{H}_{2} \mathrm{O}$. We have named these five spectral niches after their corresponding colors, as the violet, blue, green, orange and red niche (Table 1).

We mapped geographical distributions of these spectral niches by satellite remote sensing. The results reveal a conspicuous difference in spectral properties between subtropical ocean gyres where the violet niche dominates and seasonally stratified temperate waters where the blue and green niche prevail (Fig. 4a-c). This difference in underwater light spectra may explain the predominance of Prochlorococcus in subtropical gyres and the widespread distribution of PUB- and PEB-containing cyanobacteria in temperate waters. Moreover, since both Prochlorococcus and Synechococcus can absorb light in the blue niche (with dChl $b$ and PUB, respectively), our results also identify a broad range of oceanic waters where the underwater light spectrum will favor coexistence of Prochlorococcus and PUBrich Synechococcus ${ }^{10}$ (Fig. 5b). 
The distributions of the blue, green and orange spectral niches indicate that PUB-rich Synechococcus will prevail in open ocean waters, PEB-rich Synechococcus will be more abundant in coastal and mesotrophic inland waters, while PCB-rich cyanobacteria are most abundant in eutrophic lakes with relatively high CDOM contents. Indeed, a striking spatial gradient in cyanobacterial pigmentation was found in Chesapeake $\mathrm{Bay}^{37}$, from high relative abundances of PEB-rich Synechococcus in green waters of the lower bay (Fig. 4d) to high relative abundances of PCB-rich Synechococcus higher up in the bay and in the Potomac River where the orange and red spectral niche dominate (Fig. 4e,f). A similar pattern occurs in Lake Balaton (Hungary), where PEB-rich picocyanobacteria abound in the green waters of the eastern basin, whereas PCB-rich picocyanobacteria are abundant in the more productive western basin where the orange niche prevails ${ }^{38}$. In all, these results illustrate how a classification of optical water types derived from the vibrational modes of $\mathrm{H}_{2} \mathrm{O}$ has direct relevance for the biogeographical distributions of photosynthetic pigments across the lakes and oceans of our planet (Figs. 4 and 5).

The radiative transfer model predicts that some water bodies offer a single spectral niche in the lower half of the euphotic zone, whereas spectra in other water bodies may span two (green line in Fig. 2b-d) or even three spectral niches (orange line in Fig. 2b-d). This prediction is consistent with measured spectra at the euphotic depth of different water bodies. For instance, irradiance spectra measured in the North Atlantic Ocean are characterized by two peaks, separated by a depression at the $6^{\text {th }}$ harmonic at $514 \mathrm{~nm}$ (Extended Data Fig. 4). Hence, these Atlantic waters offer both a blue and a green niche for photosynthetic organisms. This also explains the high relative abundance of Synechococcus strains capable of chromatic acclimation in large parts of the North Atlantic ${ }^{9}$ (Fig. 5a). PUB captures the blue niche, whereas PEB captures the green niche. By dynamically adjusting their PUB:PEB ratio, these chromatic acclimators can optimally tune their pigment composition to the relative availability of these two spectral niches, which may vary seasonally.

Although our analysis focused on cyanobacteria, photosynthetic pigments of eukaryotic algae also appear to be well adapted to the spectral niches demarcated by the harmonics of the water molecule. Green algae use Chl $a$ and $b$ in their light-harvesting complex, and therefore have similar light absorption spectra as Prochlorococcus (Fig. 3a). Chl a captures the violet and red niche and $\mathrm{Chl} b$ the blue and orange niche. The typical orange $\mathrm{Chl} b$ shoulder at 630-660 nm adjacent to the red Chl $a$ peak at 660-690 nm in in-vivo absorption spectra of green algae nicely resembles the shoulder-and-peak structure in the spectral landscapes (magenta line in Fig. 2b-d). In vivo, the ubiquitous 6-carotene and several other carotenoids absorb strongly in the blue niche ${ }^{12}$, whereas absorption by fucoxanthins (diatoms, 
haptophytes, brown algae) and peridinin (dinoflagellates) in the 470-540 nm range ${ }^{12,40}$ spans both the blue and green niche. Although absorption spectra of fucoxanthins and peridinin do not show an imprint of the $6^{\text {th }}$ harmonic, they are well tuned to mesotrophic waters such as the temperate North Atlantic and many coastal waters where the blue and green niche cooccur (Extended Data Fig. 4). Finally, red algae, cryptophytes and glaucophytes deploy a quite similar combination of phycobilin pigments and $\mathrm{Chl} a$ as cyanobacteria, and hence the spectral niches identified for phycobilisome-containing cyanobacteria (Fig. 3b-d) likely extend to these eukaryotic taxa as well.

In recent years, the color of many lakes and coastal waters across the northern hemisphere has changed, due to increasing CDOM concentrations as a consequence of alterations in land use, acid deposition and climate change ${ }^{41 і ̈ 43}$. Increasing CDOM concentrations shift the underwater light color towards longer wavelengths. For instance, a recent study of $\sim 1,000$ North American lakes showed a substantial decrease in the number of blue lakes and an increasing number of murky lakes ${ }^{44}$, caused by what has been called the ǵrreeningôand óbrowningôof lake waters. In terms of the spectral niches identified by our study, lake browning implies that increasing CDOM concentrations shift phytoplankton photosynthesis from the blue and green niche to the orange and red niche. Controlled experiments in field mesocosms ${ }^{45-48}$ and lakes ${ }^{49}$ have shown that lake browning leads to major changes in phytoplankton community structure, including an overall decline of green algae and diatoms ${ }^{46}$ and an increase of freshwater cyanobacteria and cryptophytes ${ }^{45 i} 49$. These findings are further supported by recent laboratory competition experiments ${ }^{10,50}$, where green algae won the competition in violet-blue light whereas PCB-rich cyanobacteria won in orange-red light. Chlorophylls and carotenoids of green algae and diatoms absorb effectively in the violet and blue niche, whereas the phycobilins PEB and PCB of freshwater cyanobacteria and cryptophytes exploit the green and orange niche. Hence, the observed changes in taxonomic composition due to lake browning match expectations based on the spectral niches advanced in this study.

The approach outlined here can be further improved in several ways. For example, phytoplankton community dynamics depend on many other factors in addition to the underwater light spectrum (e.g., nutrients, temperature, turbulence, grazing), which may all play a role in the biogeographical distributions of phytoplankton species ${ }^{51,52}$. Satellite observations are limited to the surface layers of the ocean and our analysis therefore implicitly assumed that concentrations of dissolved and detrital matter do not change drastically with depth. Furthermore, underwater light spectra span the entire PAR range near the water surface, and narrow down to a few spectral niches in the lower half of the euphotic 
zone (Fig. 2b-d). Stratified waters may therefore provide ample opportunities for vertical niche separation ${ }^{53,54}$, where light absorption by phytoplankton in the surface layer may affect the light spectrum still available for other phytoplankton deeper down in the water column. Conversely, vertical mixing can result in high relative abundances of low-light adapted Prochlorococcus in the surface layer ${ }^{22,54}$. Extending our 2D global maps to a more comprehensive 3D approach $^{55}$, to predict depth-dependent variation in CDOM and cyanobacterial pigment types across the globe, would therefore be a major step forward.

Other important next steps will include further advancement of methods to detect the spectral niches by satellite remote sensing, and application of this knowledge to assess how environmental change will affect the color of lakes ${ }^{42-44}$ and oceans ${ }^{56,57}$, and hence the species composition of phytoplankton communities. Moreover, if we can predict spectral niches for photosynthesis on our planet from first principles, then it might also be of interest to apply this approach to explore potential spectral niches on other Earth-like planets.

\section{Methods}

\section{Implementation of radiative transfer theory}

Radiative transfer equations: The propagation of light through water is modeled by radiative transfer equations, which describe how changes in spectral radiance with depth depend on absorbing and scattering components in the water column ${ }^{11,12,19}$. In natural waters, light enters from above and is attenuated with depth. If the water body is horizontally homogeneous and bottom reflectance and fluorescence can be ignored, the change in monochromatic spectral radiance $L\left(\mathrm{~W} \mathrm{~m}^{-2} \mathrm{sr}^{-1} \mathrm{~nm}^{-1}\right)$ with depth $z$ at wavelength ris given by ${ }^{11,12}$ :

$$
\frac{(,,,)}{=-,}(,,)+{ }^{*}(,,,)
$$

where $=\cos$ accounts for the vertical projection of radiance $L$ in the direction defined by the azimuth angle and zenith angle . The term $c(, z)$ is the beam attenuation coefficient $\left(\mathrm{m}^{-1}\right)$ describing the radiance lost due to absorption and scattering when passing through the water column and ${ }^{*}(,, \quad)$ is the radiance gained due to scattering from adjacent paths.

The beam attenuation coefficient is defined as:

$$
(,)=(,)+(,)
$$

where $a(\lambda, z)\left(\mathrm{m}^{-1}\right)$ is the total absorption and $b(\lambda, z)\left(\mathrm{m}^{-1}\right)$ is the total scattering coefficient at wavelength $\lambda$ and depth $z$. In turn, these coefficients are defined by the absorbing and scattering components in the water column such that:

and 


$$
\text { , }=,+\quad+\quad,
$$

The subscript $w$ refers to pure water, phyt to phytoplankton, NAP to non-algal particles and CDOM to colored (chromophoric) dissolved organic matter. The CDOM term in Eq. 4 is excluded since scattering by CDOM is negligible ${ }^{11}$.

Numerical solutions: All model calculations were performed by Ecolight, which is a variant of Hydrolight, a state-of-the-art model that solves the radiative transfer equations numerically ${ }^{19}$. The model couples a sky radiance model, air-water interface model, bottom reflection model and bio-optical model to calculate the radiance distribution with respect to zenith angle $\theta$ and azimuth angle $\varphi$ at each specified depth $z$. For our purpose, we are only interested in the irradiance at depth $z$ and so solving the azimuthally averaged radiance suffices. Ecolight solves this problem and is computationally less intensive than Hydrolight ${ }^{19}$. Ecolight was initialized with the parameter values listed in Supplementary Table 1.

Planar and scalar irradiance: From all Ecolight output, we analyzed the planar and scalar irradiance spectra. By integrating the radiance originating from the upper hemisphere with respect to solid angle $\omega$ we obtain the planar irradiance $\left(\mathrm{W} \mathrm{m}^{-2} \mathrm{~nm}^{-1}\right)$, or downward irradiance:

$$
, \quad=(\partial, \quad) \cos
$$

Phytoplankton, if approximated as spherical entities, absorb light from all directions equally. Therefore, in terms of the energy available for phytoplankton, it is useful to consider the scalar irradiance. The scalar irradiance is defined as the total radiant flux per $\mathrm{m}^{2}$ from all directions at a given point in the medium

$$
,=(,,)
$$

Euphotic depth: The euphotic depth $\left(z_{e u}\right)$ is defined as the depth at which the photosynthetically active radiation (PAR, integrated over $400-700 \mathrm{~nm}$ ) is $1 \%$ of its surface value. Because photosynthesis relies on the number of absorbed photons, PAR was expressed as photon flux in quanta $\mathrm{m}^{-2} \mathrm{~s}^{-1}$ rather than as energy flux in $\mathrm{W} \mathrm{m}^{-2}$.

First, each Ecolight run solved the radiative transfer equations to obtain spectra of scalar irradiance at 20 equidistant depths across the euphotic zone to minimize computation time and to maximize accuracy. Subsequently, the scalar irradiance spectra were transformed from $\mathrm{W} \mathrm{m}^{-2} \mathrm{~nm}^{-1}$ to quanta $\mathrm{m}^{-2} \mathrm{~s}^{-1} \mathrm{~nm}^{-1}$, and then integrated over the PAR range from 400 to $700 \mathrm{~nm}$. Because the model was based on discrete layers, the euphotic depth was approximated by interpolation: 
where the true value of the euphotic depth is bounded by the depth interval $\left[z_{1}, z_{2}\right]$ and where $I_{e u}, I_{1}, I_{2}$ denote the integrated scalar irradiance from 400 to $700 \mathrm{~nm}$ at depth $z_{e u}, z_{1}$ and $z_{2}$ respectively. The irradiance spectra were subsequently interpolated between depth $z_{1}$ and $z_{2}$ to approximate the spectrum at the euphotic depth:

$$
\ln (,)=\ln (,)+(-) \frac{(,)(,)}{(,)}
$$

where $E_{0}\left(\lambda, z_{e u}\right), E_{0}\left(\lambda, z_{1}\right)$ and $E_{0}\left(\lambda, z_{2}\right)$ denote the scalar irradiance at wavelength and depths $z_{e u}, z_{1}$ and $z_{2}$ respectively.

\section{Inherent optical properties (IOPs)}

Below we briefly describe the optical properties of water, NAP and CDOM, and by doing so we specify the absorption and scattering terms in Eqs. 3 and 4.

Water absorption $\ddot{\mathrm{i}}$ The absorption properties of pure water have been well characterized ${ }^{15 i}$ ${ }^{18}$. Absorption by pure water is highest at the red end of the PAR range and decreases toward shorter wavelengths, reaching a minimum in the UV range at $344 \mathrm{~nm}$. Harmonics and subharmonics of the vibrational stretching and bending modes of the water molecule show as shoulders in the PAR range of the absorption spectrum (Fig. 1). All calculations were performed with the absorption coefficients of Pope $\&$ Fry $^{17}$ for wavelengths $>550 \mathrm{~nm}$, whereas updated coefficients for wavelengths $<550 \mathrm{~nm}$ were obtained from Mason et al. ${ }^{18}$.

Water scattering ï Elastic scattering by water molecules is inversely proportional to the fourth power of the wavelength (i.e., $\quad \propto \quad$ ). Hence, pure water scatters violet and blue light much more strongly than red light ${ }^{11,12}$.

Our Ecolight simulations also include Raman scattering (inelastic scattering) ${ }^{11,19}$. Effects of Raman scattering are minor in comparison to absorption and elastic scattering, but can be observed in clear ocean waters at short wavelengths $(400-500 \mathrm{~nm})$ as a subtle increase in photons that have been re-emitted mainly from the UV.

CDOM absorption ï CDOM is an important optical component in water. Absorption by $\mathrm{CDOM}$ is highest in the violet and blue part of the light spectrum and can be described as an exponentially decreasing function of wavelength ${ }^{58}$ (Extended Data Fig. 1):

$$
=\quad \exp -(-)
$$


where $a_{C D O M}(\lambda)$ is the absorption by CDOM at wavelength $\lambda, a_{\text {СDOM }}\left(\lambda_{0}\right)$ the absorption by CDOM at reference wavelength $\lambda_{0}$ and $S$ describes the exponential slope of the curve. The slope $S$ varies slightly for different waters ${ }^{58 i ̈ 60}$, with values ranging from 0.01 to $0.02 \mathrm{~nm}^{-1}$. We take $\lambda_{0}=440 \mathrm{~nm}$ as our reference wavelength and a typical value of $S=0.017 \mathrm{~nm}^{-1}$ for the slope ${ }^{4,12,60}$. The value of $a_{C D O M}\left(\lambda_{0}\right)$ depends on the CDOM concentration. We varied CDOM absorption, from $a_{\text {СDом }}(440)=0.0025 \mathrm{~m}^{-1}$ indicative of very clear ocean waters with extremely low CDOM concentrations ${ }^{14}$ to $\operatorname{aCDOM}_{\text {C }}(440)=20 \mathrm{~m}^{-1}$ representative of highly turbid lakes with very high CDOM concentrations ${ }^{12}$.

NAP absorption ï Non-algal-particles (NAP), also referred to as suspended material or tripton, include both mineral particles (e.g., sand, clay) and detritus (dead particulate organic matter). Absorption by NAP can exceed the combined absorption by pure water and CDOM, especially in waters with high concentrations of suspended material. Similar to CDOM, absorption spectra of NAP usually have low absorption in the red and increasing absorption towards the violet and blue end of the spectrum. Hence, absorption by NAP can be described by an exponential decay function similar to Eq. 9, with slope $S$ typically being smaller for NAP than for CDOM. The spectral slope $S$ ranges from 0.006 to $0.014 \mathrm{~nm}^{-1}$ (refs. 59,60). Since absorption by organic matter is already included in the model (via CDOM), we characterized absorption by NAP using an average of the absorption spectra for calcareous sand, yellow clay, red clay and brown earth ${ }^{19}$ (Extended Data Fig. 1). To compare waters with different concentrations of suspended materials, the absorption value $a_{N A P}\left(\lambda_{0}\right)$ at the reference wavelength of $440 \mathrm{~nm}$ is varied from $0.0025 \mathrm{~m}^{-1}$ to $20 \mathrm{~m}^{-1}$, the same range as we applied to $a_{\text {СDОM }}\left(\lambda_{0}\right)$. These absorption values correspond to NAP concentrations that range from $0.04 \mathrm{mg} / \mathrm{m}^{3}$ for the clearest oceanic waters to $320 \mathrm{mg} / \mathrm{m}^{3}$ for turbid waters with extremely high sediment loads.

NAP scattering Ï Natural waters have much higher scattering coefficients than pure water due to the contribution of suspended particles. The intensity of scattering spans several orders of magnitude from low scattering environments such as clear open ocean waters to highly scattering turbid rivers. The size of suspended particles plays an important role in the scattering behavior ${ }^{13,61 i ̈ 63}$.

The wavelength dependence of the scattering coefficient is less certain. Although the particulate scattering fraction $\left(b_{p}=b_{N A P}+b_{p h y t}\right)$ can be obtained by subtracting the contribution of water $\left(b_{w}\right)$ from the total scattering coefficient $(b)$, the relationship between wavelength and in-situ measurements of $b$ varies among different waterbodies ${ }^{62}$. The wavelength 
dependence of $b_{N A P}$, when expressed as a power law (

$\propto \quad$ ), ranges from $\gamma=0.65$ for inshore waters to $\gamma=2.0$ for open waters ${ }^{12}$. Here we make use of an average of the massspecific scattering spectra for calcareous sand, yellow clay, red clay and brown earth ${ }^{19}$ (Extended Data Fig. 1) and use the Petzold volume scattering function to describe the angular distribution of the scattered light ${ }^{12,64,65}$.

Absorption and scattering by phytoplankton ï Phytoplankton can strongly affect absorption and scattering in aquatic ecosystems. In our application, however, we aim to derive the spectral niches created by the abiotic environment, i.e., the light spectra available for the initial establishment of phytoplankton populations. Therefore, we set $a_{\text {phyt }}(\lambda, z)=b_{\text {phyt }}(\lambda, z)=0$.

\section{Measured irradiance spectra}

We collected underwater irradiance spectra from different water bodies spanning a wide range of light conditions (Extended Data Fig. 4).

The irradiance spectrum of the South Pacific subtropical gyre is from Morel et al. ${ }^{14}$. We measured irradiance spectra of the North Pacific subtropical gyre during cruise HOT-174 with the RV Kilo Moana (October 2005) and of the Baltic Sea during cruise Cyano-04 with the $R V$ Aranda (July 2004). Two spectra in the North Atlantic Ocean were kindly measured by our colleague Dr. Michael Kehoe (University of Amsterdam) during the STRATIPHYT II cruise with the RV Pelagia (April 2011). Irradiance spectra of Lake IJsselmeer (September 2004) and Lake á Joppe (September 2006) were measured from the RV Luctor and a small rowing boat, respectively. At each station, depth profiles of downward irradiance spectra were measured at a $3.3 \mathrm{~nm}$ spectral resolution using a RAMSES-ACC-VIS spectroradiometer (TriOS, Oldenburg, Germany) equipped with a cosine collector. Underwater irradiance spectra were corrected for temporal variation in incident solar irradiance measured simultaneously by a second RAMSES-ACC-VIS placed above the water surface. The euphotic depth was estimated as the depth at which the downward irradiance (integrated over the PAR range from $400-700 \mathrm{~nm}$, in quanta $\mathrm{m}^{-2} \mathrm{~s}^{-1}$ ) was $1 \%$ of the downward irradiance measured just below the water surface.

\section{Relative availability of spectral niches}

Which spectral niche dominates the underwater light field of a given aquatic ecosystem? To address this question, we define the relative availability of a spectral niche as the fraction of the total scalar irradiance at the euphotic depth that falls within this spectral niche: 
where $r_{n}$ is the relative availability of the $n^{\text {th }}$ spectral niche (violet, blue, green, orange or red), $E_{0}\left(\lambda, z_{e u}\right)$ is the scalar irradiance of wavelength $\lambda$ at the euphotic depth, and $\lambda_{1}$ and $\lambda_{2}$ are the wavelengths of the two harmonics that demarcate the $n^{\text {th }}$ spectral niche.

\section{Absorption spectra of cyanobacteria}

Light absorption spectra were obtained from marine Prochlorococcus and Synechococcus/ Cyanobium strains representative of the major picocyanobacterial pigment types ${ }^{27}$.

We used light absorption spectra of a low-light (LL) adapted and a high-light (HL) adapted Prochlorococcus strain published by Moore et al. ${ }^{25}$. The LL-adapted strain was $P$. marinus SS120 isolated from $120 \mathrm{~m}$ depth in the Sargasso Sea and grown at $3 \mu \mathrm{mol}$ photons $\mathrm{m}^{-2} \mathrm{~s}^{-1}$. The HL-adapted strain was P. marinus MED4 isolated from surface waters of the Mediterranean Sea and grown at $61 \mu \mathrm{mol}$ photons $\mathrm{m}^{-2} \mathrm{~s}^{-1}$. See Moore et al. ${ }^{25}$ for experimental details.

The Synechococcus/Cyanobium strains included Synechococcus MEDNS5 (PUB-rich strain), Synechococcus WH7803 (PEB-rich strain with low PUB:PEB ratio), Synechococcus PROSOPE_97-4 (PEB-rich strain without PUB), and Cyanobium CCY9201 (PCB-rich strain; previously described ${ }^{3}$ as Synechococcus BS4). These strains were grown in laboratory erlenmeyers provided with white light at $20 \mu \mathrm{mol}$ photons $\mathrm{m}^{-2} \mathrm{~s}^{-1}$ and a nutrient-rich mineral medium ${ }^{3}$ supplemented with $\mathrm{NaCl}$ to a salinity of $12 \mathrm{mg} \mathrm{L}^{-1}$ for Cyanobium CCY9201 originating from the Baltic Sea and $35 \mathrm{mg} \mathrm{L}^{-1}$ for the three marine Synechococcus strains. During the exponential growth phase, absorbance spectra were measured from 400 to $750 \mathrm{~nm}$ with $0.3 \mathrm{~nm}$ resolution using an updated Aminco DW2000 double-beam spectrophotometer (OLIS, Lombard, AL, USA). Mineral medium without phytoplankton was used as a control.

All absorbance spectra were normalized to Chl $a$ absorbance at $440 \mathrm{~nm}$, after baseline correction for minimum absorbance at $750 \mathrm{~nm}$.

\section{Satellite retrieval of dissolved and detrital absorption coefficients}

According to the radiative transfer model, the relative availability of the spectral niches depends on light absorption by dissolved and detrital matter (i.e., by CDOM and NAP) (Extended Data Fig. 5). Absorption coefficients of dissolved and detrital matter $\left(a_{\mathrm{dg}}\right)$ can be estimated from satellite retrievals of the inherent optical properties of surface waters. The Ocean Colour Climate Change Initiative (OC-CCI, https://www.oceancolour.org) of the European Space Agency (ESA) provides retrievals of inherent optical properties across the 
global ocean at an average spatial resolution of $4 \mathrm{~km}$ and at a variety of wavelengths. We use version 4.0 of the ESA OC-CCI dataset for estimation of absorption coefficients of dissolved and detrital matter at $443 \mathrm{~nm}$, defined as $a_{\mathrm{dg}}(443)=a_{\mathrm{CDOM}}(443)+a_{\mathrm{NAP}}(443)$. Monthly averaged measurements of $a_{\mathrm{dg}}(443)$ for April 2016 provided maximum global coverage and were used as input for the radiative transfer model to map the spectral niches in Fig. 4.

To compare data from the marine stations with satellite retrievals of dissolved and detrital absorption (Fig. 5b), we used weekly averaged measurements of $a_{\mathrm{dg}}(443)$. Each marine station was matched by geographical coordinates and sampling date to the corresponding satellite measurement of $a_{\mathrm{dg}}(443)$. Nearest neighbor interpolation (in space) was used if no valid $a_{\mathrm{dg}}(443)$ retrieval was present at the location of the sampling station.

\section{Biogeographical data}

We collected data on the relative abundances of cyanobacterial pigment types from surface waters of 54 marine stations ${ }^{9,22}, 9$ stations in the brackish Baltic $\mathrm{Sea}^{7}$ and 59 lake stations ${ }^{5 i} 7$ (Supplementary Table 2).

Relative abundances of marine Prochlorococcus and Synechococcus were obtained from surface waters sampled by the Tara Oceans expedition as reported in Farrant et al. ${ }^{22}$, based on normalized numbers of metagenomic petB reads taxonomically assigned to either Prochlorococcus or Synechococcus. Since this gene is present in both genera in single copy, the relative number of reads is assumed to provide a fairly good proxy of the relative abundances of Prochlorococcus and Synechococcus.

Relative abundances of Synechococcus pigment types at the same marine stations were obtained from Grébert et al. ${ }^{9}$, based on metagenomics reads of three distinct marker genes ( which resulted in four main categories:

1) PCB-rich types $=\mathrm{PT} 1$

2) PEB-rich types $=$ PT2 \& PT3a

3) Chromatic acclimators $=$ PT3dA \& PT3dB

4) PUB-rich types $=$ PT3c \& PT3f

where PT $x$ refers to the pigment types distinguished in previous classifications ${ }^{9,27}$.

The chromatic acclimators (PT3dA and PT3dB) are Synechococcus spp. capable of adjusting their PUB:PEB ratio to match the ambient light color ${ }^{9}$. At a number of stations in HNLC regions of the Southern Pacific and Indian Ocean, Synechococcus spp. that were originally assigned as PT3dA by Grébert et al. ${ }^{9}$ contained only part of the gene set necessary for chromatic acclimation. Phenotypic characterization of a laboratory isolate (BIOS-E4-1) 
displaying the same genotype showed that these ónatural mutantsôwere incapable of chromatic acclimation and displayed the phenotype of PUB-rich pigment types (PT3c) ${ }^{9}$. These natural mutants were therefore assigned to the PUB-rich types in our study.

Relative abundances of Synechococcus pigment types in lakes and the Baltic Sea were obtained from studies of Pick ${ }^{5}$ for lakes in Canada and New Zealand, Vörös et al. ${ }^{6}$ for lakes in Hungary, Italy and Nepal, and Stomp et al. ${ }^{7}$ for stations in the Baltic Sea. Cell counts in Pick ${ }^{5}$ and Vörös et al. ${ }^{6}$ were based on epifluorescence microscopy, whereas Stomp et al. ${ }^{7}$ used flow cytometry. Both epifluorescence microscopy and flow cytometry can distinguish between PCB-rich, PEB-rich and PUB-rich cells, but cannot identify whether these cells are capable of chromatic acclimation.

Prochlorococcus absorbs in both the violet and blue niche. Therefore, relative abundances of Prochlorococcus were compared with the co-occurrence of the violet and blue niche, $r_{\text {violet } x b l u e}$, which we defined as the product of the relative availabilities of both niches:

$$
\times()=4 \times \quad() \times \quad(\quad)
$$

The factor 4 ensures that $r_{\text {violet } x b l u e}$ varies in the range $[0,1]$, as implied by the constraint $r_{\text {violet }}$ $+r_{\text {blue }} \leq 1$.

Phycobilisome-containing cyanobacteria such as Synechococcus have a much higher photosynthetic efficiency in blue, green and orange light absorbed by their phycobilisomes than in violet light absorbed by $\mathrm{Chl} a^{10,33}$. Hence, we compared relative abundances of the different pigment types of Synechococcus with relative availabilities of the blue, green and orange niche absorbed by their phycobilins PUB, PEB and PCB, respectively. Chromatic acclimators containing both PUB and PEB capture light in both the blue and green niche. Relative abundances of these chromatic acclimators were therefore compared with the cooccurrence of the blue and green niche, defined in a similar way as in Eq. 11 above.

\section{Data availability}

Datasets of all spectra shown in this study (Figs. 1-3, Extended Data Figs. 1-5) are available at [url figshare, to be added once doi is available].

Remote sensing data that support the findings of this study are available from the Ocean Colour Climate Change Initiative of the European Space Agency, http://www.oceancolour.org

Relative abundance data of cyanobacterial pigment types are obtained from Refs. 5-7, 9 and 22, and available in Supplementary Table 2.

\section{Code availability}


R scripts used to generate Figs. 2 and 4 are available at:

https://github.com/tadzi/spectral_niches_photosynthesis

\section{References}

1. Engelmann, T. W. Über Sauerstoffausscheidung von Pflanzenzellen im Mikrospektrum. Bot. Zeit. 40, $419 \ddot{~} 426$ (1882).

2. Engelmann, T. W. Farbe und assimilation. Bot. Zeit. 41, 1 ï 29 (1883).

3. Stomp, M. et al. Adaptive divergence in pigment composition promotes phytoplankton biodiversity. Nature 432, 10410107 (2004).

4. Stomp, M., Huisman, J., Stal, L. J. \& Matthijs, H. C. P. Colorful niches of phototrophic microorganisms shaped by vibrations of the water molecule. ISME J. 1, 271 ï 282 (2007).

5. Pick, F. R. The abundance and composition of freshwater picocyanobacteria in relation to light penetration. Limnol. Oceanogr. 36, $1457 і ̈ 1462$ (1991).

6. Vörös, L., Callieri, C., Balogh, K. V. \& Bertoni, R. Freshwater picocyanobacteria along a trophic gradient and light quality range. Hydrobiologia 369ї 370, 117 ï 125 (1998).

7. Stomp, M. et al. Colourful coexistence of red and green picocyanobacteria in lakes and seas. Ecol. Lett. 10, $290 і ̈ 298$ (2007).

8. Ting, C. S., Rocap, G., King, J. \& Chisholm, S. W. Cyanobacterial photosynthesis in the oceans: the origins and significance of divergent light-harvesting strategies. Trends Microbiol. 10, 134ї 142 (2002).

9. Grébert, T. et al. Light color acclimation is a key process in the global ocean distribution of Synechococcus cyanobacteria. Proc. Natl Acad. Sci. U.S.A. 115, E2010-E2019 (2018).

10. Luimstra. V. M., Verspagen, J. M. H., Xu, T., Schuurmans, J. M. \& Huisman, J. Changes in water color shift competition between phytoplankton species with contrasting lightharvesting strategies. Ecology 101, e02951 (2020).

11. Mobley, C. D. Light and Water: Radiative Transfer in Natural Waters (Academic Press, 1994).

12. Kirk, J. T. O. Light and Photosynthesis in Aquatic Ecosystems, third edn (Cambridge University Press, 2011).

13. Dallôlmo, G., Westberry, T. K., Behrenfeld, M. J., Boss, E. \& Slade, W. H. Significant contribution of large particles to optical backscattering in the open ocean. Biogeosciences 6, $947 і ̈ 967$ (2009).

14. Morel, A. et al. Optical properties of the ñclearestònatural waters. Limnol. Oceanogr. 52, 217 ï 229 (2007). 
15. Pegau, W. S., Gray, D. \& Zaneveld, J. R. Absorption and attenuation of visible and nearinfrared light in water: dependence on temperature and salinity. Appl. Opt. 36, $6035 \mathrm{I}$ 6046 (1997).

16. Sogandares, F. M. \& Fry, E. S. Absorption spectrum (340-640 nm) of pure water. I. Photothermal measurements. Appl. Opt. 36, 8699 ï 8709 (1997).

17. Pope, R. M. \& Fry, E. S. Absorption spectrum (380ї 700 nm) of pure water. II. Integrating cavity measurements. Appl. Opt. 36, 8710 ï 8723 (1997).

18. Mason, J. D., Cone, M. T. \& Fry, E. S. Ultraviolet (250-550 nm) absorption spectrum of pure water. Appl. Opt. 55, 7163 Ï 7172 (2016).

19. Mobley, C. D. \& Sundman, L. K. HydroLight 5.3 - EcoLight 5.3 Technical Documentation (Sequoia Scientific Inc., 2016).

20. Sathyendranath, S., Brewin, R. J., Jackson, T., Mélin, F. \& Platt, T. Ocean-colour products for climate-change studies: what are their ideal characteristics? Remote Sens. Environ. 203, 125 Ï 138 (2017).

21. IOCCG Protocol Series. Inherent Optical Property Measurements and Protocols: Absorption Coefficient (International Ocean-Colour Coordinating Group (IOCCG), 2018).

22. Farrant, G. K. et al. Delineating ecologically significant taxonomic units from global patterns of marine picocyanobacteria. Proc. Natl Acad. Sci. U.S.A. 113, E3365ï E3374 (2016).

23. Chisholm, S.W. et al. Prochlorococcus marinus nov. gen. nov. sp.: an oxyphototrophic marine prokaryote containing divinyl chlorophyll $a$ and b. Arch. Microbiol. 157, 297-300 (1992).

24. Partensky, F., Hess, W. R. \& Vaulot D. Prochlorococcus, a marine photosynthetic prokaryote of global significance. Microbiol. Mol. Biol. Rev. 63, $106 i ̈ 127$ (1999).

25. Moore, L. R., Goericke, R. \& Chisholm, S. W. Comparative physiology of Synechococcus and Prochlorococcus: influence of light and temperature on growth, pigments, fluorescence and absorptive properties. Mar. Ecol. Prog. Ser. 116, 259 ï 275 (1995).

26. Tandeau de Marsac, N. Phycobiliproteins and phycobilisomes: the early observations. Photosynth. Res. 76, 193 ï 205 (2003).

27. Six, C. et al. Diversity and evolution of phycobilisomes in marine Synechococcus spp.: a comparative genomics study. Genome Biol. 8, R259 (2007).

28. Watanabe, M \& Ikeuchi, M. Phycobilisome: architecture of a light-harvesting supercomplex. Photosynth. Res. 116, 265 Ï 276 (2013). 
29. Sanfilippo, J. E., Garczarek, L., Partensky, F. \& Kehoe, D. M. Chromatic acclimation in cyanobacteria: a diverse and widespread process for optimizing photosynthesis. Annu. Rev. Microbiol. 73, $407 i ̈ 433$ (2019).

30. Palenik, B. Chromatic adaptation in marine Synechococcus strains. Appl. Environ. Microbiol. 67, $991 і ̈ 994$ (2001).

31. Stomp, M. et al. The timescale of phenotypic plasticity and its impact on competition in fluctuating environments. Am. Nat. 172, E169ї E185 (2008).

32. Hirose, Y. et al. Diverse chromatic acclimation processes regulating phycoerythrocyanin and rod-shaped phycobilisome in cyanobacteria. Mol. Plant 12, 715 ï 725 (2019).

33. Luimstra, V. M. et al. Blue light reduces photosynthetic efficiency of cyanobacteria through an imbalance between photosystems I and II. Photosynth. Res. 138, $177 i ̈ 189$ (2018).

34. Humily, F. et al. A gene island with two possible configurations is involved in chromatic acclimation in marine Synechococcus. PLoS ONE 8, e84459 (2013).

35. Haverkamp, T. et al. Diversity and phylogeny of Baltic Sea picocyanobacteria inferred from their ITS and phycobiliprotein operons. Environ. Microbiol. 10, 174ї 188 (2008).

36. Huisman, J. et al. Cyanobacterial blooms. Nat. Rev. Microbiol. 16, 471 Ï 483 (2018).

37. Chen, F. et al. Phylogenetic diversity of Synechococcus in the Chesapeake Bay revealed by Ribulose-1,5-bisphosphate carboxylase-oxygenase (RuBisCO) large subunit gene (rbcL) sequences. Aquat. Microb. Ecol. 36, $1531 ̈ 164$ (2004).

38. Somogyi, B., Felföldi, T., Tóth, L.G., Bernát, G. \& Vörös, L. Photoautotrophic picoplankton: a review on their occurrence, role and diversity in Lake Balaton. Biologia Futura, in press (2020). https://doi.org/10.1007/s42977-020-00030-8

39. Kardinaal, W. E. A. et al. Competition for light between toxic and nontoxic strains of the harmful cyanobacterium Microcystis. Appl. Environ. Microbiol. 73, 2939 ï 2946 (2007).

40. Bricaud, A., Claustre, H., Ras, J. \& Oubelkheir, K. Natural variability of phytoplanktonic absorption in oceanic waters: influence of the size structure of algal populations. $J$. Geophys. Res. 109, C11010 (2004).

41. Monteith, D. T. et al. Dissolved organic carbon trends resulting from changes in atmospheric deposition chemistry. Nature 450, 537 ï 541 (2007).

42. Weyhenmeyer, G. A., Müller, R. A., Norman, M. \& Tranvik, L. J. Sensitivity of freshwaters to browning in response to future climate change. Clim. Change 134, $225 \mathrm{I}$ 239 (2016).

43. Kritzberg, E. S. Centennial-long trends of lake browning show major effect of afforestation. Limnol. Oceanogr. Lett. 2, $105 і ̈ 112$ (2017). 
44. Leech, D. M., Pollard, A. I., S. G. \& Hampton, S. E. Fewer blue lakes and more murky lakes across the continental U.S.: implications for planktonic food webs. Limnol. Oceanogr. 63, 2661 2680 (2018).

45. Ekvall, M. K. et al. Synergistic and species-specific effects of climate change and water colour on cyanobacterial toxicity and bloom formation. Freshw. Biol. 58, 2414ї 2422 (2013).

46. Urrutia-Cordero, P. et al. Phytoplankton diversity loss along a gradient of future warming and brownification in freshwater mesocosms. Freshw. Biol. 62, 1869ï 1878 (2017).

47. Wilken, S. et al. Primary producers or consumers? Increasing phytoplankton bacterivory along a gradient of lake warming and browning. Limnol. Oceanogr. 63, S142ï S155 (2018).

48. Feuchtmayr, H. et al. Effects of brownification and warming on algal blooms, metabolism and higher trophic levels in productive shallow lake mesocosms. Sci. Tot. Env. 678, 227ï 238 (2019).

49. Deininger, A., Faithfull, C. L. \& Bergström, A. K. Phytoplankton response to whole lake inorganic $\mathrm{N}$ fertilization along a gradient in dissolved organic carbon. Ecology 98, 982ï 994 (2017).

50. Tan, X., Zhang, D., Duan, Z., Parajuli, K. \& Hu, J. Effects of light color on interspecific competition between Microcystis aeruginosa and Chlorella pyrenoidosa in batch experiment. Environ. Sci. Pollut. Res. 27, 344 ï 352 (2020).

51. Burson, A., Stomp, M., Greenwell, E., Grosse, J. \& Huisman, J. Competition for nutrients and light: testing advances in resource competition with a natural phytoplankton community. Ecology 99, $1108 і ̈ 1118$ (2018).

52. Dutkiewicz, S. et al. Dimensions of marine phytoplankton diversity. Biogeosciences 17, $609 і ̈ 634$ (2020).

53. Johnson, Z. I. et al. Niche partitioning among Prochlorococcus ecotypes along oceanscale environmental gradients. Science 311, $1737 і ̈ 1740$ (2006).

54. Malmstrom, R. R. et al. Temporal dynamics of Prochlorococcus ecotypes in the Atlantic and Pacific oceans. ISME J. 4, $1252 i ̈ 1264$ (2010).

55. Lange, P. K. et al. Scratching beneath the surface: a model to predict the vertical distribution of Prochlorococcus using remote sensing. Remote Sens. 10, 847 (2018).

56. Wernand, M. R., van der Woerd, H. J. \& Gieskes, W. W. C. Trends in ocean colour and chlorophyll concentration from 1889 to 2000, worldwide. PLOS ONE 8, e63766 (2013). 
57. Dutkiewicz, S. et al. Ocean colour signature of climate change. Nat. Comm. 10, 578 (2019).

58. Bricaud, A., Morel, A. \& Prieur, L. Absorption by dissolved organic matter of the sea (yellow substance) in the UV and visible domains. Limnol. Oceanogr. 26, 431 53 (1981).

59. Twardowski, M. S., Boss, E., Sullivan, J. M. \& Donaghay, P. L. Modeling the spectral shape of absorption by chromophoric dissolved organic matter. Mar. Chem. 89, 6910 88 (2004).

60. Babin, M. et al. Variations in the light absorption coefficients of phytoplankton, nonalgal particles, and dissolved organic matter in coastal waters around Europe. J. Geophys. Res. 108, 1 20 (2003).

61. Babin, M., Morel, A., Fournier-Sicre, V., Fell, F. \& Stramski, D. Light scattering properties of marine particles in coastal and open ocean waters as related to the particle mass concentration. Limnol. Oceanogr. 48, 843 Ï 859 (2003).

62. Doxaran, D. et al. Spectral variations of light scattering by marine particles in coastal waters, from the visible to the near infrared. Limnol. Oceanogr. 54, 1257ï 1271 (2009).

63. Nechad, B., Ruddick, K. G. \& Park, Y. Calibration and validation of a generic multisensor algorithm for mapping of total suspended matter in turbid waters. Remote Sens. Environ. 114, $854 і ̈ 866$ (2010).

64. Petzold, T. J. Volume Scattering Functions for Selected Ocean Waters (No. SIO-REF72-78). (Scripps Institution of Oceanography, La Jolla CA, 1972).

65. Morel, A. \& Gentili, B. Diffuse reflectance of oceanic waters: its dependence on sun angle as influenced by the molecular scattering contribution. Appl. Opt. 30, 4427 ï 4438 (1991).

66. Sanfilippo, J. E. et al. Interplay between differentially expressed enzymes contributes to light color acclimation in marine Synechococcus. Proc. Natl Acad. Sci. U.S.A. 116, 64576462 (2019).

Acknowledgments: This article is dedicated to the memory of our late colleagues Dr. Maayke Stomp and Dr. Hans C.P. Matthijs, who provided a source of inspiration for our understanding of the spectral niches for cyanobacterial photosynthesis. We thank Giorgio Dallôlmo and Ricardo M. Letelier for constructive comments on previous versions of the manuscript, Michael Kehoe (University of Amsterdam) for measuring underwater spectra of the North Atlantic during the STRATIPHYT II cruise, Veerle M. Luimstra (University of Amsterdam) for help with the cyanobacterial absorption spectra, and Frances R. Pick (University of Ottawa) and Lajos Vörös (Hungarian Academy of Sciences) for sampling of 
lake stations. We thank the Tara Oceans coordinators and consortium for support, and the captains and crew of the Tara schooner for sampling of the marine stations.

Funding: This research was funded by the Dutch Research Council (NWO) under grant ALW-GO 14-06 and a VENI-grant to M. Stomp, and by the French Agence Nationale de la Recherche (ANR) programs CINNAMON (ANR-17-CE02-0014-01) and EFFICACY (ANR-19-CE02-0019).

Author contributions: M.S. and J.H. conceived the original idea, and designed the study in collaboration with H.J.v.d.W. The radiative transfer model was run by T.H. and H.J.v.d.W. Underwater light spectra were measured by M.S. and J.H. Remote sensing data were analyzed by T.H., L.B. and H.J.v.d.W. Absorption spectra of cyanobacteria were measured by M.S., J.H. and L.G. Biogeographical distributions of the pigment types were collected by T.G., F.P. and L.G. for the marine stations and by M.S. and J.H. for the lake stations and Baltic Sea. T.H. made the figures. J.H. and T.H. wrote the manuscript, and all authors except our late colleague M.S. commented on the final version.

Competing interests: The authors declare no competing interests.

Extended Data. Extended Data Figures 1-6.

Extended Data Fig. 1. Inherent optical properties of colored dissolved organic matter (CDOM) and non-algal particles (NAP).

a, Absorption spectrum of CDOM; scattering by CDOM is negligible. b, Absorption and scattering spectrum of NAP used in our application (see Methods for details).

\section{Extended Data Fig. 2. Predictions of a null model in which the vibrational modes of $\mathrm{H}_{2} \mathrm{O}$} are ignored.

a, In the null model, the absorption spectrum of water (blue-gray line) is replaced by a smooth absorption spectrum (magenta line) without the subtle shoulders of the vibrational harmonics. b, Overlay of hundred underwater scalar irradiance spectra at the euphotic depth for waters with different CDOM concentrations, calculated by the null model. The null model does not predict a spectral landscape with pronounced peaks and valleys (in contrast to models that incorporate the vibrational modes of $\mathrm{H}_{2} \mathrm{O}$; see Fig. 2 in the main text).

Extended Data Fig. 3. Absorption spectra of chromatic acclimators grown in different light colors. 
a, Fluorescence excitation spectra of Synechococcus A15-62, a chromatic acclimator that adjusts its PUB:PEB ratio. The spectra show excitation wavelengths absorbed by the cells and subsequently emitted by the phycobilisomes as fluorescence at $580 \mathrm{~nm}$, when the cells are grown in blue light (blue line) or green light (green line). b, Absorption spectra of Pseudanabaena CCY9509, a chromatic acclimator that adjusts its PEB:PCB ratio. The absorption spectra are shown for cells acclimated to green light (green line), orange light (orange line), and midway during chromatic acclimation after a switch from green to orange light (black line). The spectra are normalized with respect to (a) the PEB peak at $\sim 540 \mathrm{~nm}$, and (b) the Chl-a peak at $440 \mathrm{~nm}$. Spectra in (a) were measured in this study using methods described in Sanfilippo et al. ${ }^{66}$, whereas spectra in (b) are from Stomp et al. ${ }^{31}$. For comparison, grey peaks and valleys in the background show simulated underwater irradiance spectra and vertical dashed lines indicate the harmonics of the water molecule.

\section{Extended Data Fig. 4. Comparison of simulated and measured irradiance spectra, for aquatic ecosystems ranging from the clearest ocean waters to a hypertrophic lake.}

a, Simulated planar irradiance spectra at the euphotic depth for a wide range of CDOM concentrations. b, Measured planar irradiance spectra at the euphotic depth in 7 different aquatic ecosystems. The spectra were obtained from (1) the South Pacific gyre (near Easter Island), (2) North Pacific gyre (station ALOHA north of Hawaii), (3) subtropical North Atlantic (Canary Islands), (4) temperate North Atlantic (west of Ireland), (5) Baltic Sea (near Gulf of Finland), (6) lake IJsselmeer (Netherlands) and (7) lake á Joppe (Netherlands). Simulated irradiance spectra in (a) that qualitatively resemble measured irradiance spectra in (b) are indicated by the same color. The irradiance spectrum of the South Pacific gyre is from Morel et al. ${ }^{14}$; all other spectra were measured in this study. Locations of the measured spectra are mapped in Fig. 5a. Vertical dashed lines indicate the harmonics of the water molecule.

\section{Extended Data Fig. 5. Relative availability of the spectral niches depends on absorption by CDOM and NAP.}

The relative availability of a spectral niche is calculated by the radiative transfer model, as the fraction of the total scalar irradiance at the euphotic depth that falls within this spectral niche (see Eq. 10 in the Methods). The relative availability of the spectral niches is displayed as function of absorption by dissolved and detrital matter (i.e., CDOM and NAP) at $443 \mathrm{~nm}$ $\left(a_{d g}(443)\right)$, which is a variable that can be retrieved by satellite remote sensing. 
Extended Data Fig. 6. Relative abundances of cyanobacterial pigment types in the Great Lakes Area of North America, Central European lakes and the Baltic Sea.

a, Great Lakes Area of North America. b, Central European lakes and the Baltic Sea.

Relative abundances were estimated using epifluorescence microscopy for the lake stations $s^{5 i 7}$ and flow cytometry for stations in the Baltic $\mathrm{Sea}^{7}$ (Supplementary Table 2). Prochlorococcus and PUB-rich Synechococcus were not found at these stations. Data from nearby stations in the Baltic Sea are aggregated in single pie charts.

\section{Supplementary Information}

\section{Reporting Summary}

Supplementary Information. Supplementary Tables 1 and 2.

Supplementary Video. Interactive plot, showing scalar irradiance spectra at the euphotic depth for a wide range of CDOM and NAP concentrations. 


\section{Figure legends}

Fig. 1: Absorption properties of the water molecule. a, The three vibrational modes of the water molecule: symmetric stretching, asymmetric stretching and bending. b, Absorption spectrum (blue line) and scattering spectrum (magenta line) of pure water in the photosynthetically active range (400-700 nm). Vertical dashed lines indicate harmonics and subharmonics of the vibrational modes of the water molecule. The $n^{\text {th }}$ harmonic corresponds to the wavelength that induces a combination of $n$ symmetric and asymmetric stretching vibrations; the $n .1^{\text {st }}$ subharmonic indicates the wavelength that induces a combination of $n$ symmetric and asymmetric stretching vibrations and 1 bending vibration.

\section{Fig. 2: Spectral niches in the underwater light spectrum created by harmonics of the} vibrational modes of the water molecule. a, Total absorption spectra of pure water with different concentrations of CDOM (no NAP). CDOM absorption at $440 \mathrm{~nm}\left(a_{\mathrm{CDOM}}(440)\right)$ ranges from 0.0025 (blue line) to $20 \mathrm{~m}^{-1}$ (magenta line). b-d, Overlay of hundred underwater scalar irradiance spectra calculated for waters with different CDOM concentration using an advanced radiative transfer model ${ }^{19}$. The panels compare three optical depths, at which PAR (integrated over 400-700 $\mathrm{nm}$ ) has been attenuated to (b) 10\%, (c) 3\%, and (d) $1 \%$ of the surface irradiance (euphotic depth). This shows that subtle local maxima in the absorption spectrum of water create deep valleys in the underwater irradiance spectra. The colored irradiance spectra in (b-d) were calculated from the corresponding colored absorption spectra in (a). Vertical dashed lines indicate the harmonics of the water molecule. Design of the graphs is inspired by Stomp et al. ${ }^{4}$.

\section{Fig. 3: Absorption spectra of the main cyanobacterial pigments capture the spectral} niches created by the harmonics of the water molecule. Light absorption spectra are from a, a high-light (HL) adapted and low-light (LL) adapted Prochlorococcus strain containing different ratios of dChl $a$ and $\mathrm{dChl} b ; \mathbf{b}$, a PUB-rich Synechococcus strain; c, two PEB-rich Synechococcus strains, with either a low PUB:PEB ratio (brown line) or only PEB (magenta line); d, a PCB-rich Synechococcus strain. The corresponding phycobilisome structures of the cyanobacterial pigment types (PT1-PT3c, according to Six et al. ${ }^{27}$ ) are shown next to panels (b-d), where APC = allophycocyanin core; $\mathrm{PC}=$ phycocyanin; $\mathrm{PE}-\mathrm{I}$ and PE-II = phycoerythrin I and II. For comparison, grey peaks and valleys in the background show simulated underwater irradiance spectra; underwater spectra with the closest match with the absorption peaks of the cyanobacteria are highlighted by colored dotted lines. Vertical dashed 
lines indicate the harmonics of the water molecule. Absorption spectra of Prochlorococcus strains in (a) are from Moore et al. ${ }^{25}$; all other spectra were measured in this study.

Fig. 4: Global distribution of the five spectral niches. The geographical maps show the relative availability at the euphotic depth of the (a) violet niche, (b) blue niche, and (c) green niche across the worldô oceans, and of the (d) green niche, (e) orange niche and (f) red niche in the Chesapeake Bay area (East Coast of the USA). The maps are based on absorption by dissolved and detrital matter at $443 \mathrm{~nm}$ estimated by satellite remote sensing (data obtained from the Ocean Color Climate Change Initiative of the European Space Agency), which served as input for the radiative transfer model to predict the relative availabilities of the spectral niches.

\section{Fig. 5: Comparison of predicted spectral niches and global distributions of} cyanobacterial pigment types. a, Global distribution of pigment types of Prochlorococcus and Synechococcus. The small map in the inset shows relative abundances of Prochlorococcus (purple) and Synechococcus (white). The main map shows relative abundances of different pigment types within the Synechococcus group. Chromatic acclimators can adjust their PUB:PEB ratio. Data from nearby stations in the Great Lakes Area of North America, Central European lakes and the Baltic Sea are here aggregated in single pie charts, and expanded in Extended Data Figure 6. Numbers indicate locations of measured underwater irradiance spectra (Extended Data Fig. 4). b, Comparison of observed relative abundances of cyanobacterial pigment types (symbols) and predicted relative availability of the spectral niches (curves), as a function of absorption by dissolved and detrital matter at $443 \mathrm{~nm}\left(a_{\mathrm{dg}}(443)\right)$. The curves assume that Prochlorococcus captures both the violet and blue niche, and chromatic acclimators capture both the blue and green niche. Relative abundances of cyanobacterial pigment types were estimated using metagenomics data (squares) collected from surface waters of 54 marine stations sampled during the Tara Oceans expedition ${ }^{9,22}$, flow cytometry (triangles) of samples from 9 stations in the Baltic $\mathrm{Sea}^{7}$, and epifluorescence microscopy (circles) of samples from 59 lake stations ${ }^{5 i 7}$ (Supplementary Table 2). $\mathrm{R}^{2}$ values indicate goodness-of-fit between the observed cyanobacterial pigment types and predicted spectral niches. 
Table 1: The five spectral niches identified in this study.

\begin{tabular}{|c|c|c|c|}
\hline Spectral niche & Harmonics & $\begin{array}{l}\text { Wavelength } \\
(\mathrm{nm})\end{array}$ & $\begin{array}{l}\text { Cyanobacterial pigments } \\
\text { and their in vivo absorption peaks* }\end{array}$ \\
\hline Violet & $8^{\text {th }} \ddot{i} 7^{\text {th }}$ & $401-449$ & Chl $a(438 \mathrm{~nm}), \mathrm{dChl} a(443 \mathrm{~nm})$ \\
\hline Blue & $7^{\text {th }} \ddot{i} 6^{\text {th }}$ & 449 ï 514 & PUB (495 nm), dChl $b(473 \mathrm{~nm})$ \\
\hline Green & $6^{\text {th }} \ddot{i} 5^{\text {th }}$ & $514 \ddot{i} 605$ & $\operatorname{PEB}(550-570 \mathrm{~nm})$ \\
\hline Orange & $5^{\text {th }} \ddot{i} 4.1$ & 605 ï 662 & PCB $(630 \mathrm{~nm}), \mathrm{dChl} b(650 \mathrm{~nm})$ \\
\hline Red & $4.1 \ddot{i} 4^{\text {th }}$ & $662-742$ & Chl $a(680 \mathrm{~nm}), \mathrm{dChl} a(673 \mathrm{~nm})$ \\
\hline
\end{tabular}

*peak wavelengths are derived from the absorption spectra in Fig. 3 
Figure 1

a
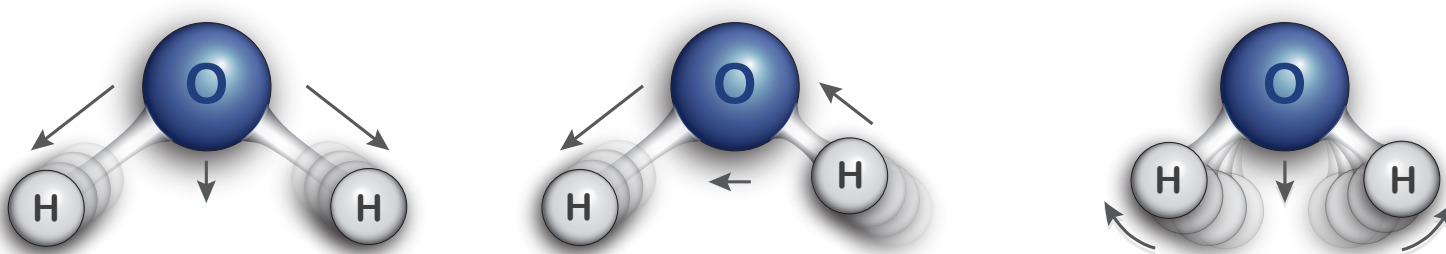

symmetric stretch

asymmetric stretch

bend

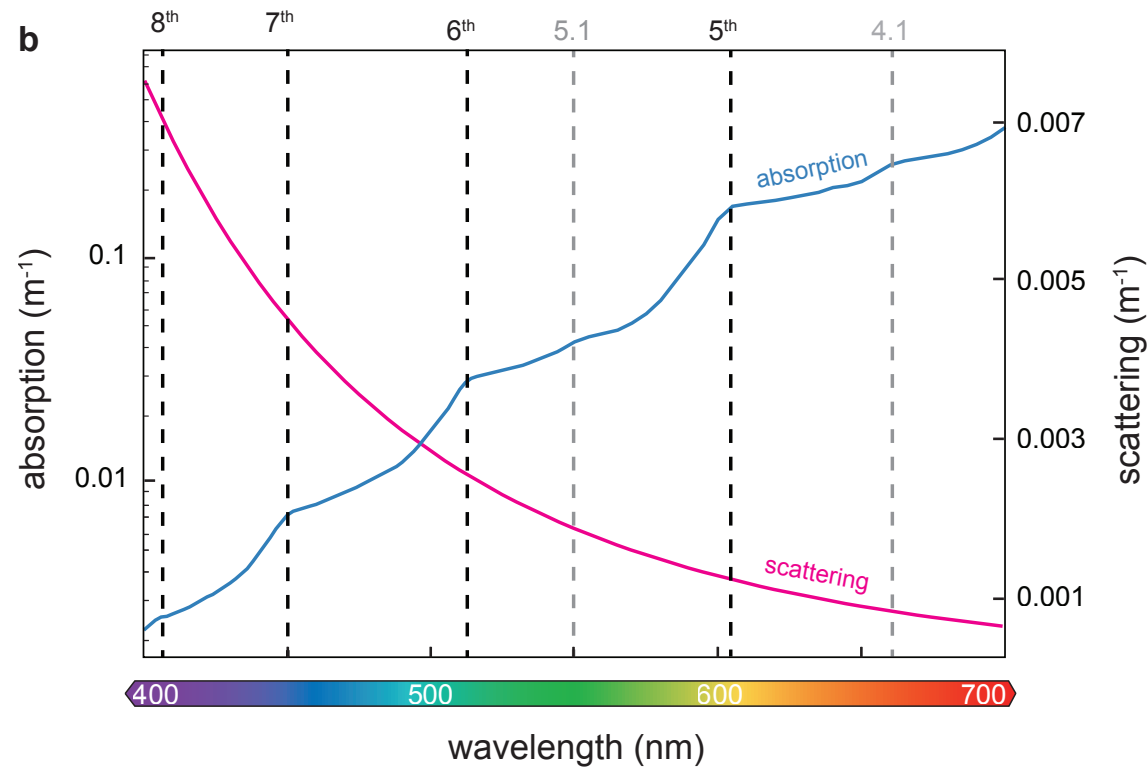




$$
\frac{m}{m}
$$


Figure 3

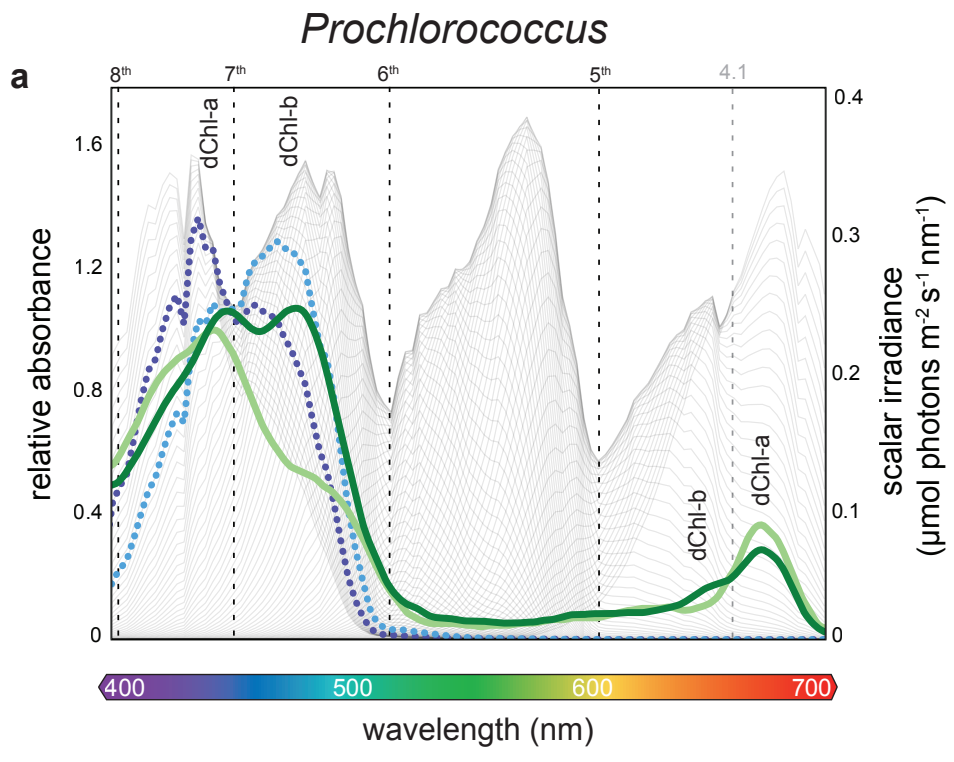

LL-adapted (SS120)

HL-adapted (MED4)
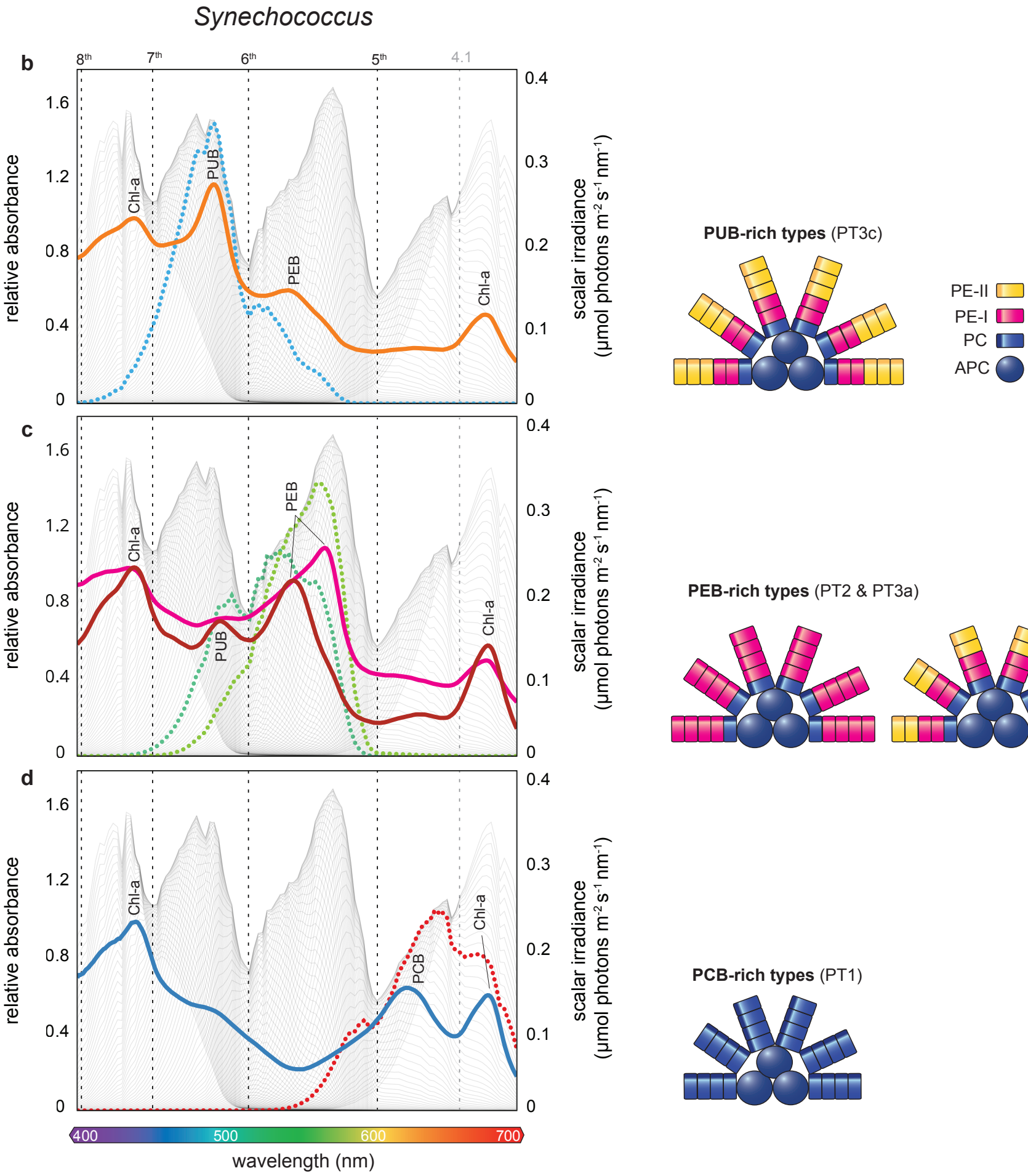

PEB-rich types (PT2 \& PT3a)
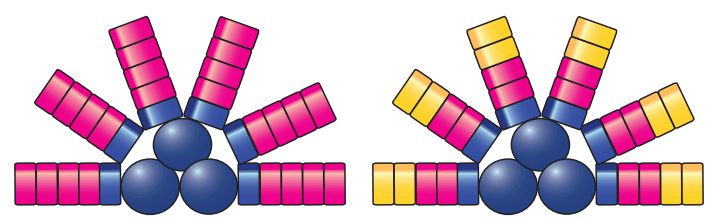

PCB-rich types (PT1)

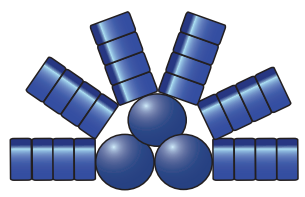


Figure 4
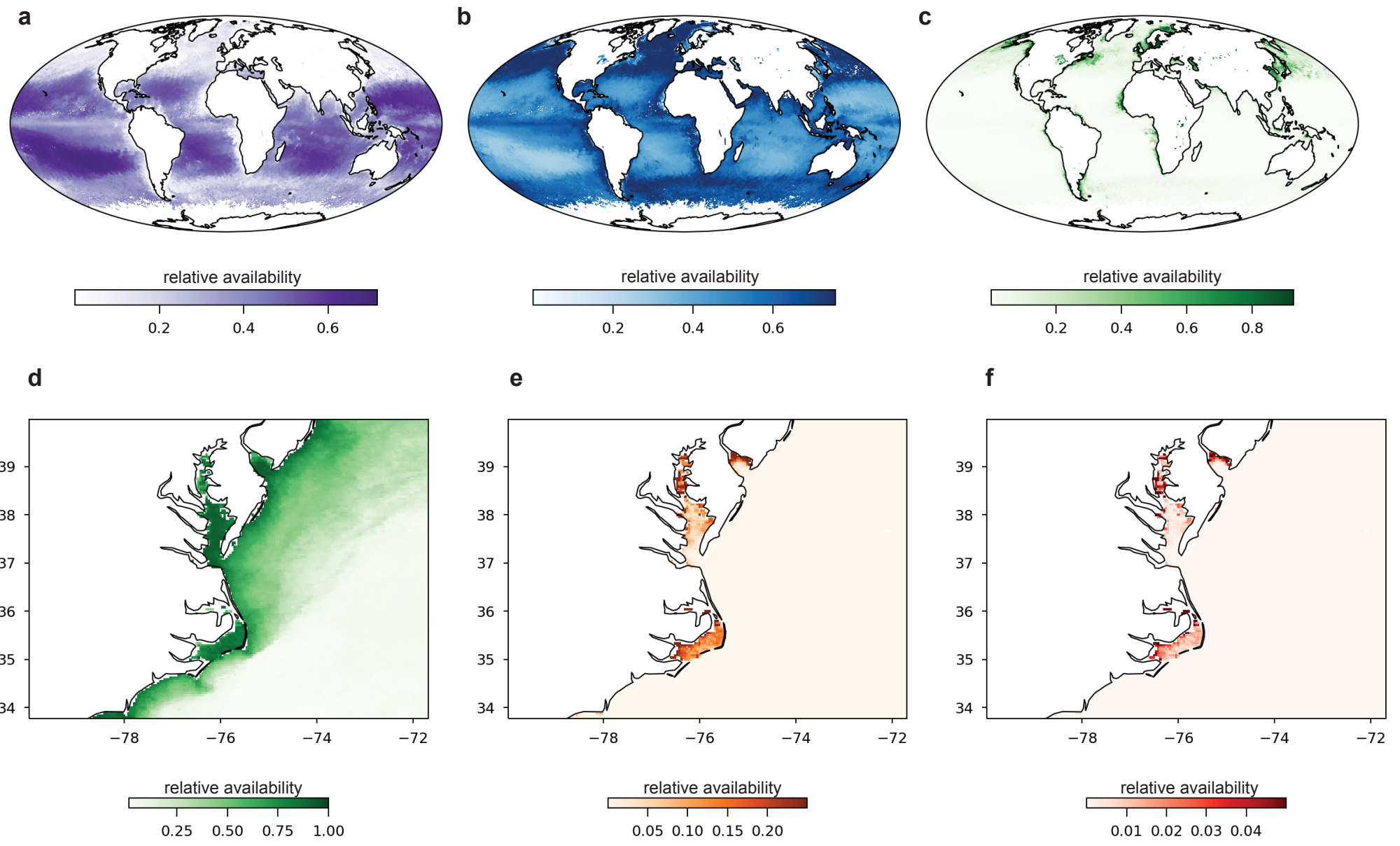
Figure 5

a

Synechococcus

Prochlorococcus

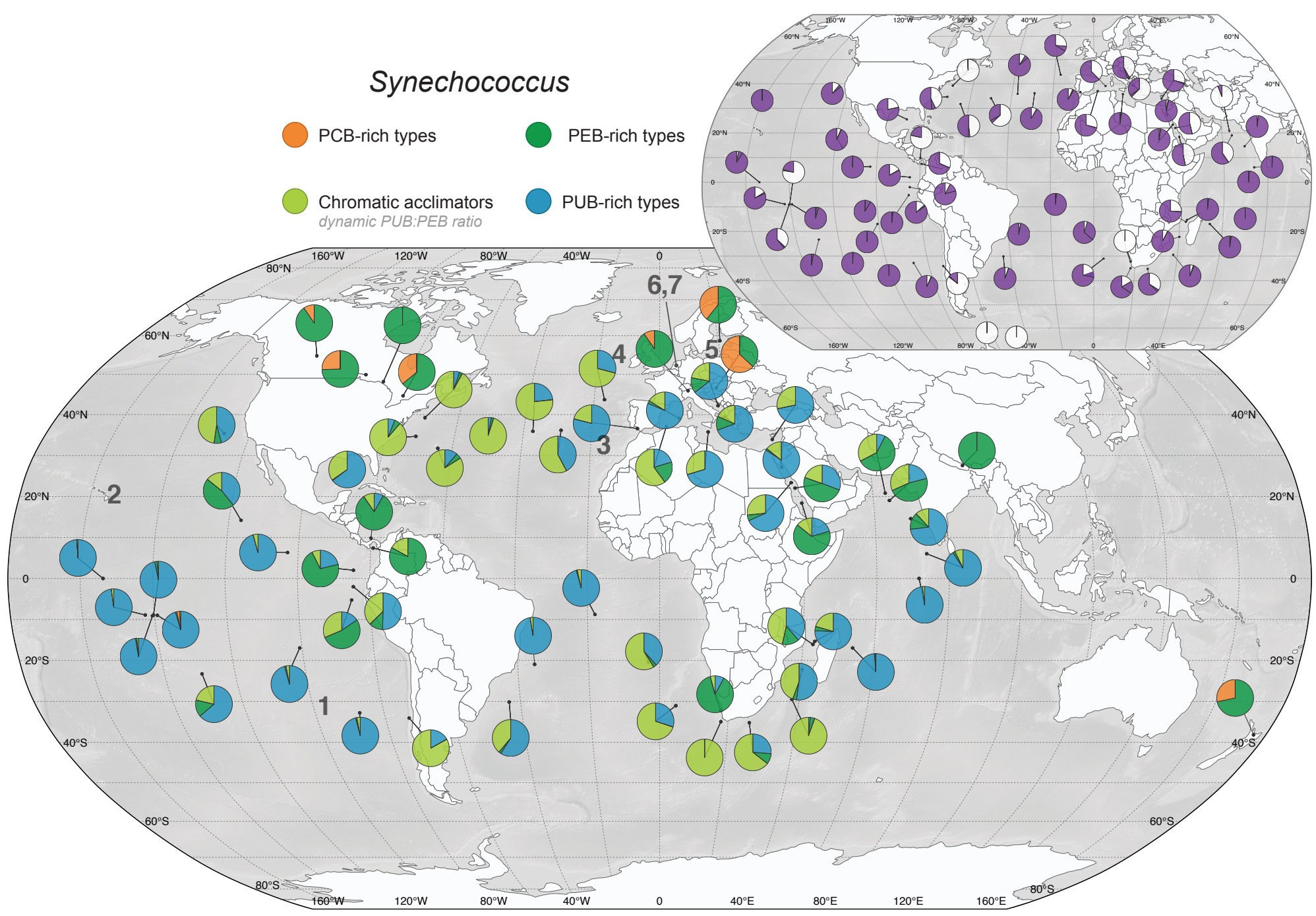

b

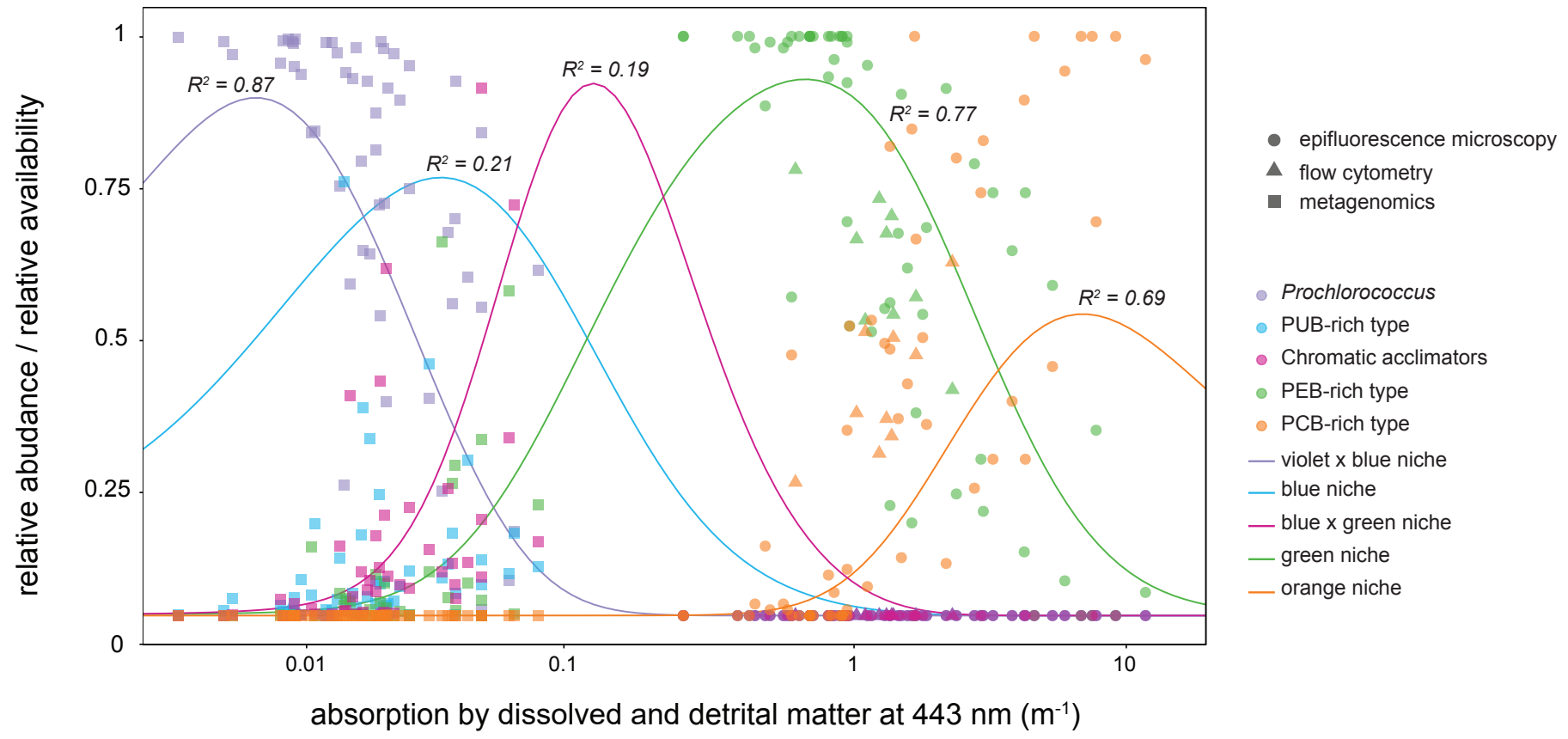


Extended Data Figure 1

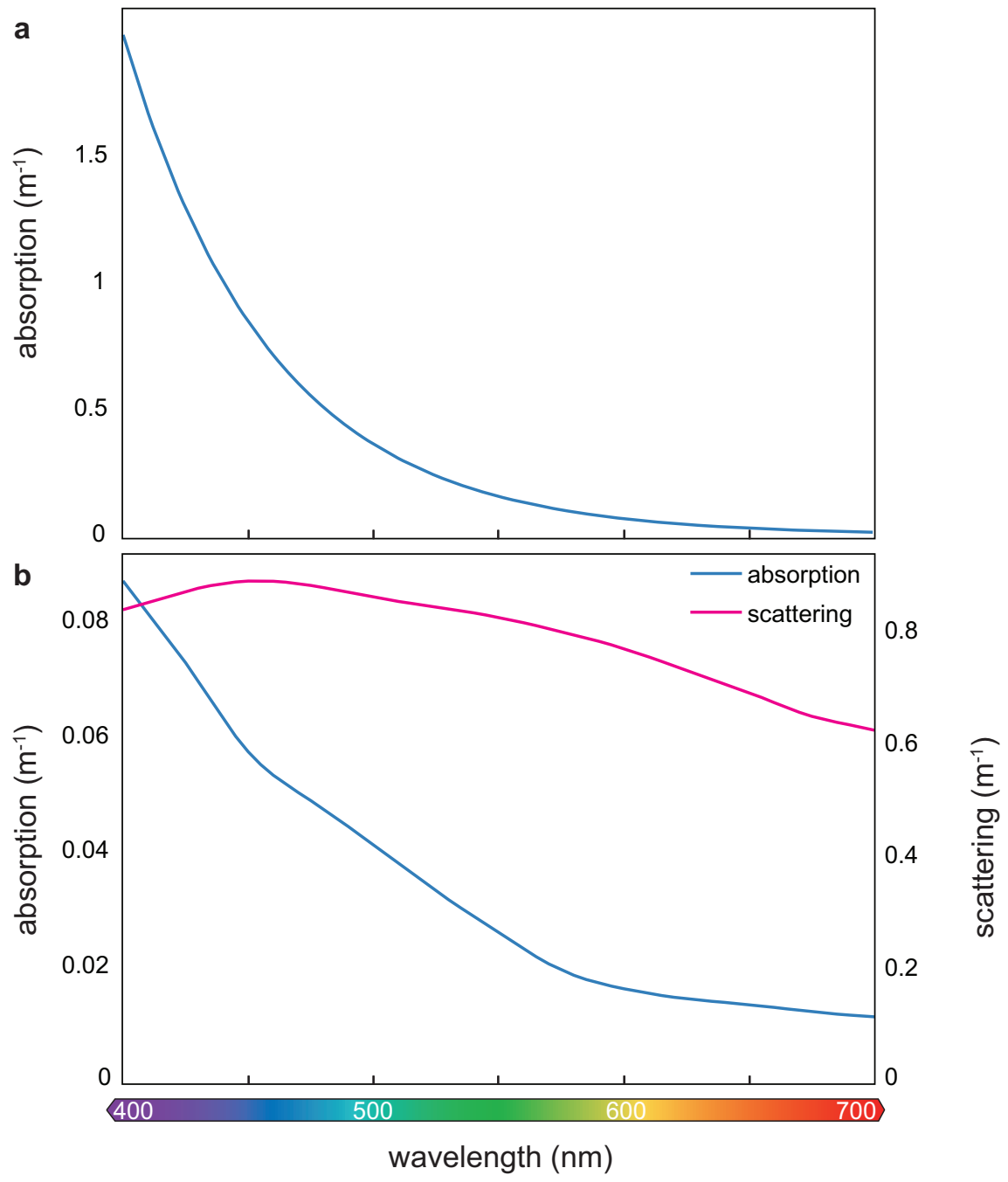




\section{Extended Data Figure 2}
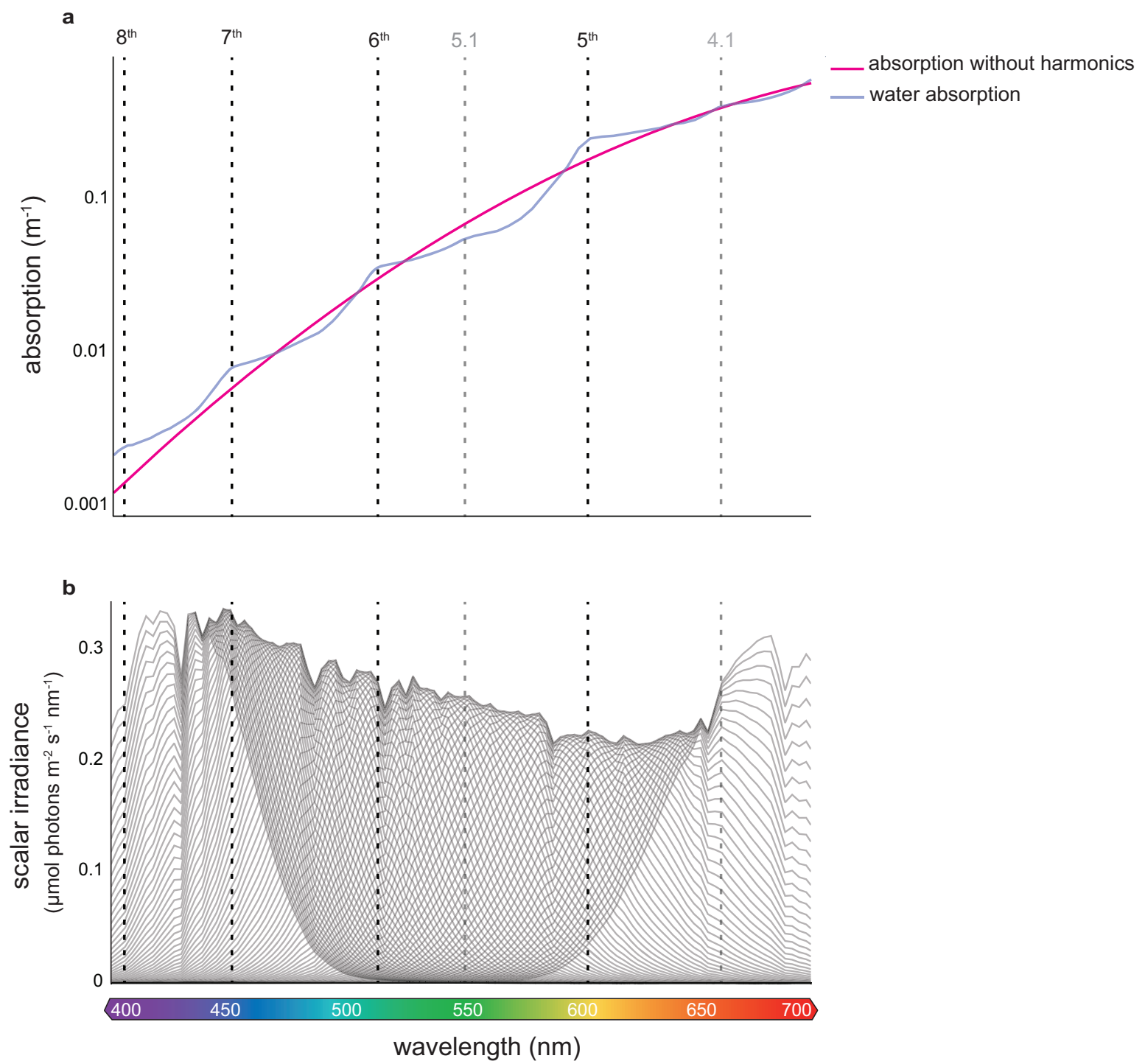


\section{Extended Data Figure 3}

a

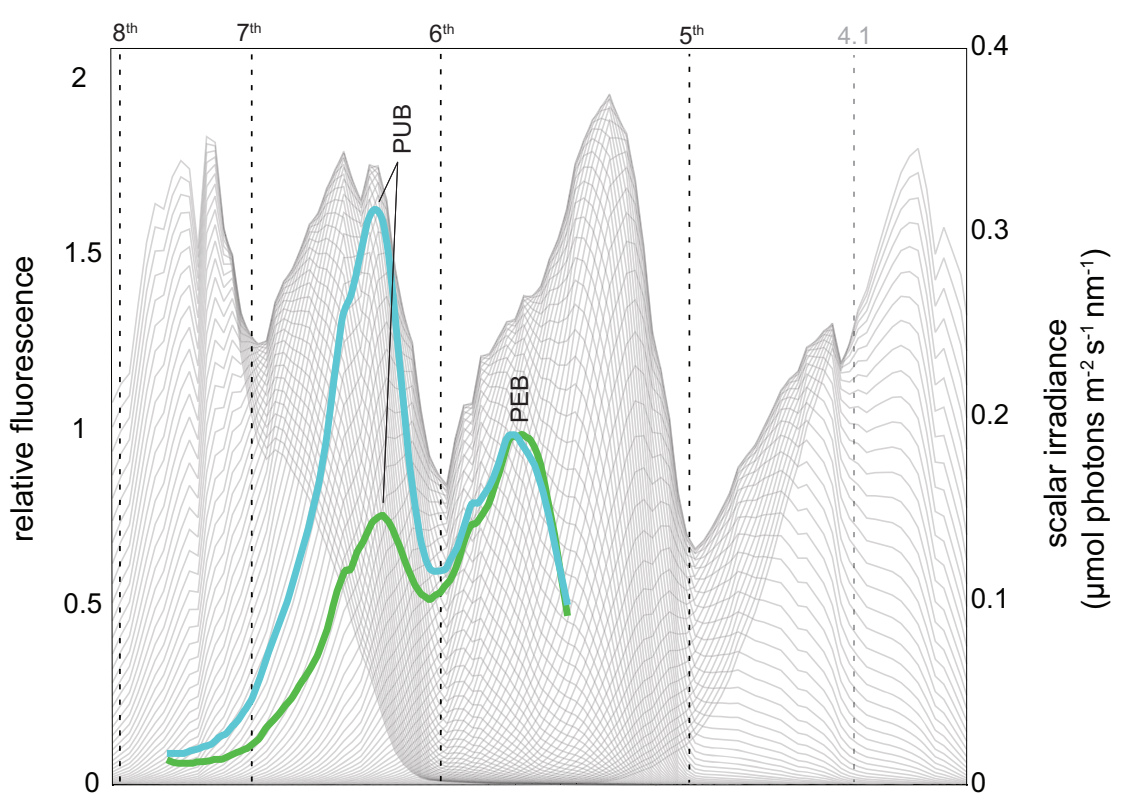

b

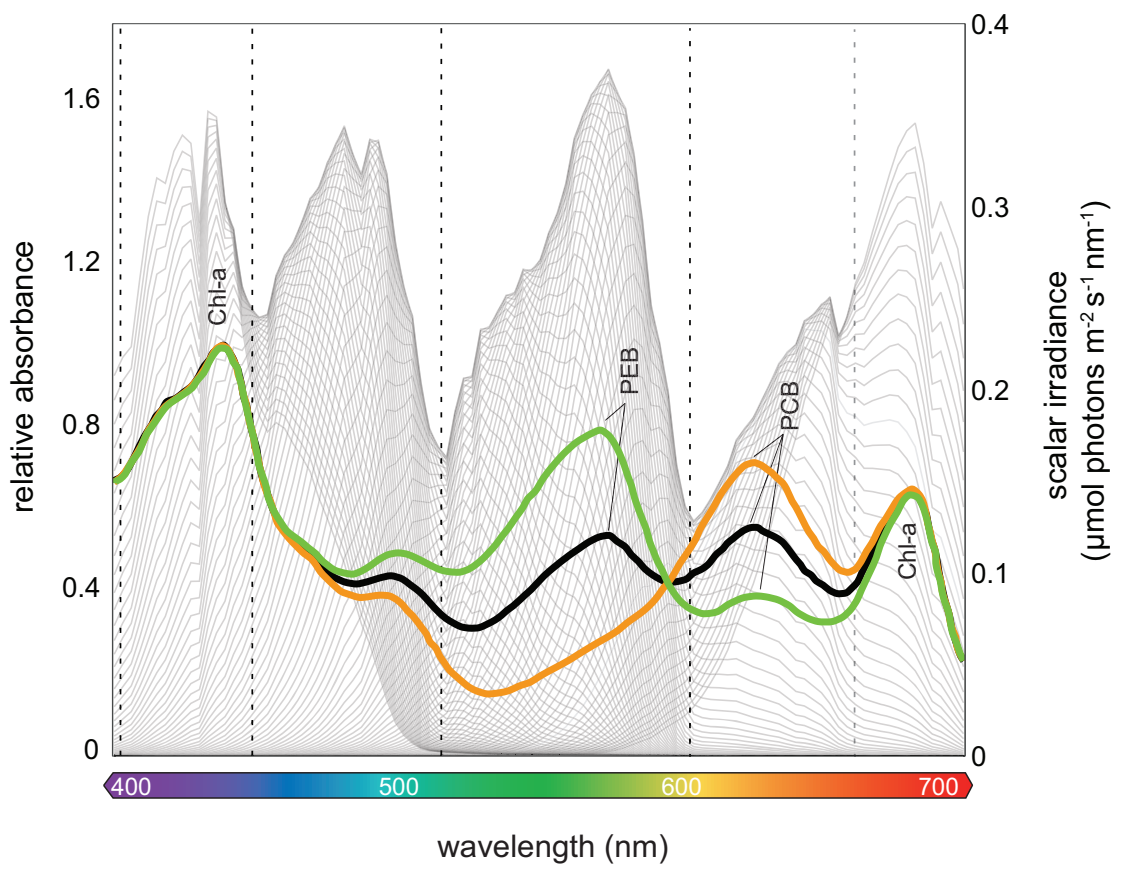




\section{Extended Data Figure 4}
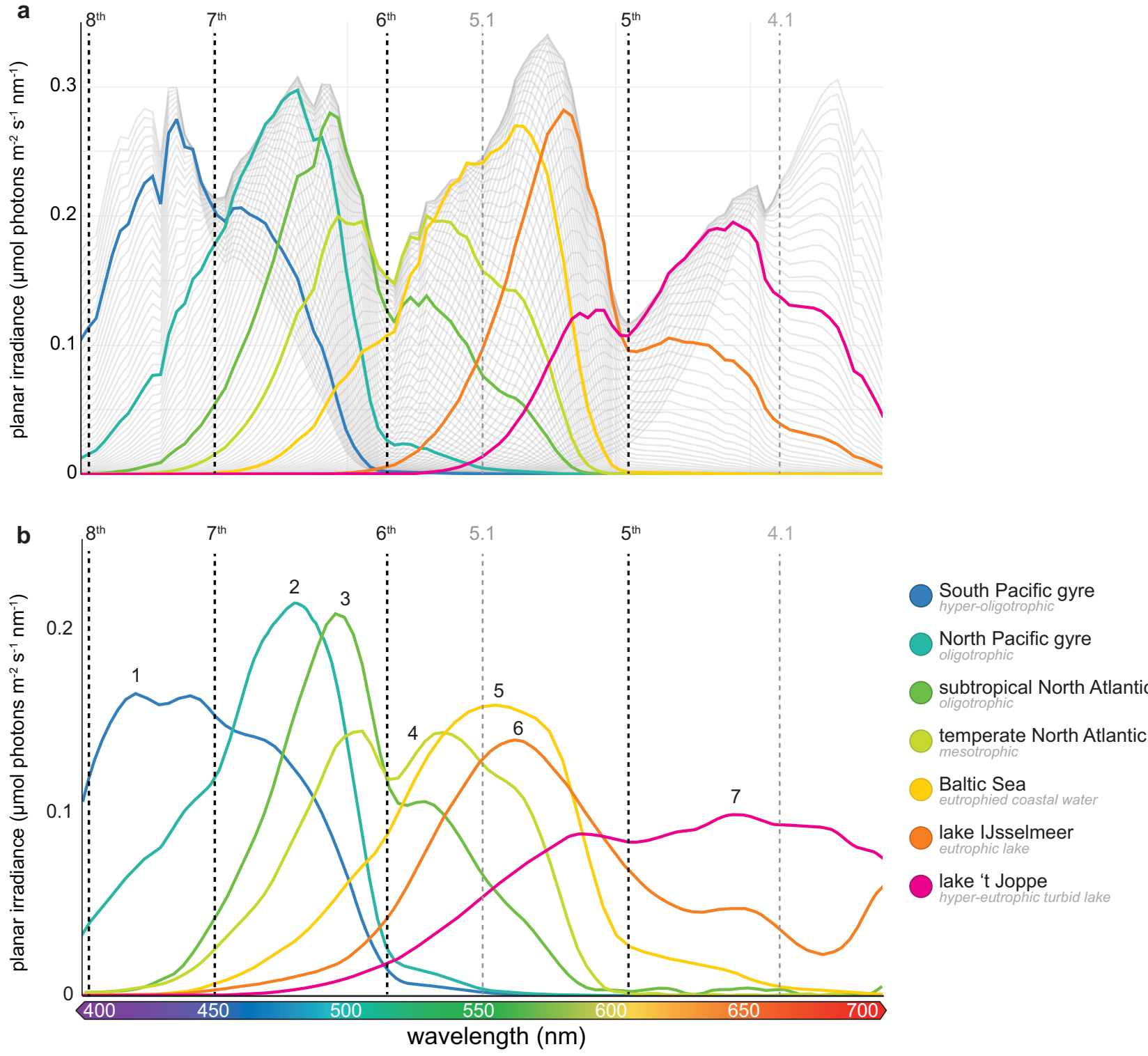
Extended Data Figure 5

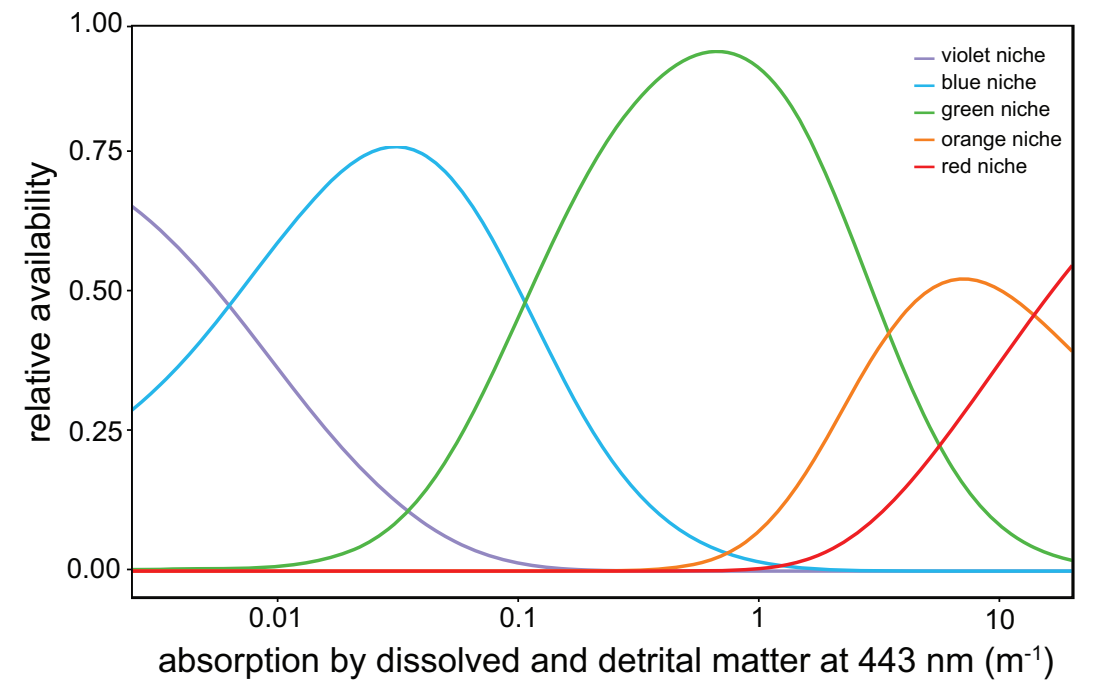




\section{Synechococcus}

PCB-rich types

PEB-rich types

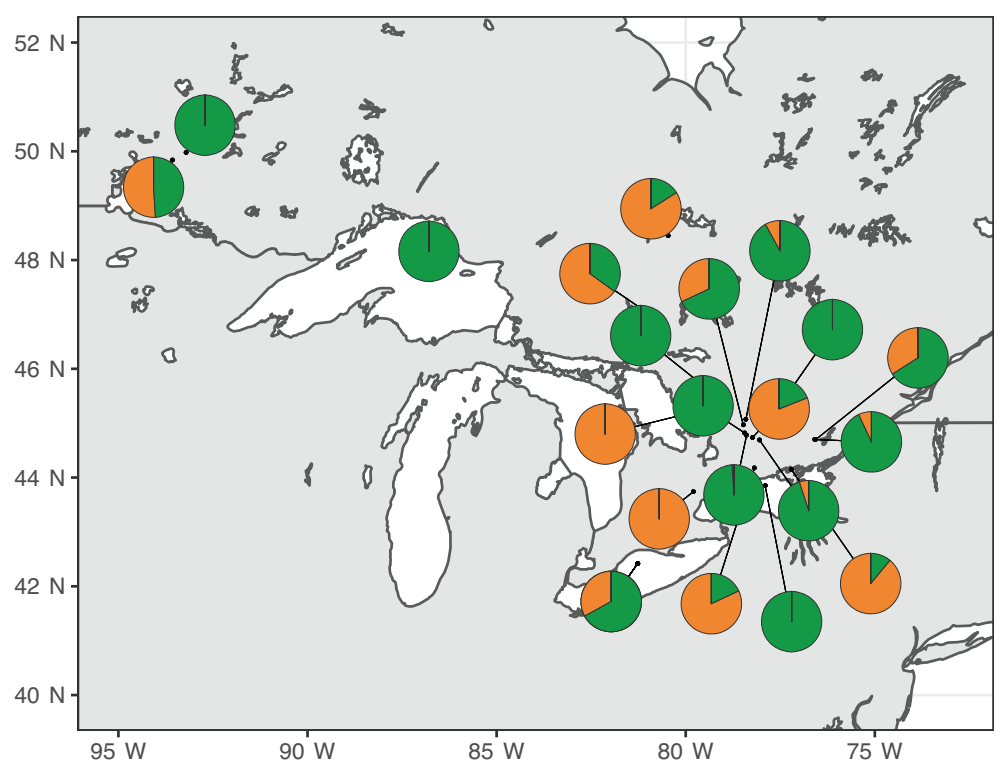

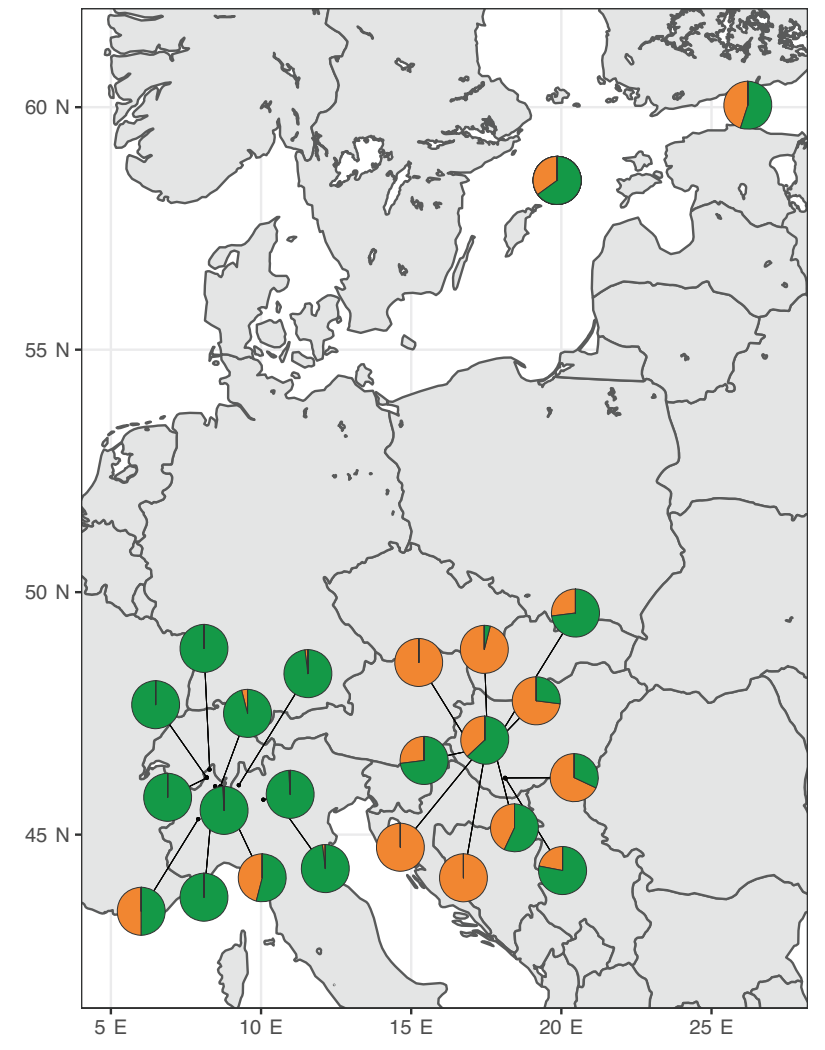




\section{Supplementary Information}

Vibrational modes of water predict spectral niches for photosynthesis in lakes and oceans

Tadzio Holtrop, Jef Huisman, Maayke Stomp, Levi Biersteker, Jeroen Aerts, Théophile Grébert, Frédéric Partensky, Laurence Garczarek \& Hendrik Jan van der Woerd

Supplementary Table 1: Hydro-Ecolight model parameters.

\begin{tabular}{|c|c|c|c|c|}
\hline Parameter & Value & Units & Notes & References \\
\hline \multicolumn{5}{|c|}{ Case-II bio-optical model } \\
\hline \multicolumn{5}{|l|}{ Sea-water } \\
\hline Absorption & - & $\mathrm{m}^{-1}$ & For absorption profile, see references & $\begin{array}{l}\text { Pope \& } \text { Fry }^{17} \text { for }>550 \mathrm{~nm} \text {; } \\
\text { Mason et al. }{ }^{18} \text { for }<550 \mathrm{~nm}\end{array}$ \\
\hline phase function & - & $\mathrm{sr}^{-1}$ & See reference & Eq 3.30 in Mobley $^{11}$ \\
\hline elastic scattering & - & $\mathrm{m}^{-1}$ & $\begin{array}{l}\text { For calculation scattering coefficient, } \\
\text { see reference }\end{array}$ & Eq 3.31 in Mobley $^{11}$ \\
\hline inelastic (Raman) scattering & - & $\mathrm{m}^{-1}$ & See reference & Mobley $^{11}$ \\
\hline \multicolumn{5}{|l|}{ Chlorophyll } \\
\hline \multicolumn{5}{|c|}{ Colored dissolved organic matter } \\
\hline$a_{C D O M}(440)$ & $\begin{array}{l}0.0025 \ddot{i} \\
20\end{array}$ & $\mathrm{~m}^{-1}$ & $\begin{array}{l}\text { Wide range of CDOM absorption at } \\
\text { reference wavelength of } 440 \mathrm{~nm}\end{array}$ & \\
\hline$S$ & 0.017 & $\mathrm{~nm}^{-1}$ & $\begin{array}{l}\text { Exponential decay function with } \\
\text { reference at } 440 \mathrm{~nm}\end{array}$ & Bricaud et al. ${ }^{58}$ \\
\hline \multicolumn{5}{|l|}{ Non-algal particles } \\
\hline$a_{N A P}(440)$ & $\begin{array}{l}0.0025 i ̈ \\
20\end{array}$ & $\mathrm{~m}^{-1}$ & $\begin{array}{l}\text { Wide range of NAP absorption at } \\
\text { reference wavelength of } 440 \mathrm{~nm}\end{array}$ & \\
\hline Absorption & - & $\mathrm{m}^{-1}$ & $\begin{array}{l}\text { For absorption profile, see Extended } \\
\text { Data Figure } 1\end{array}$ & Mobley \& Sundman ${ }^{19}$ \\
\hline Scattering & - & $\mathrm{m}^{-1}$ & $\begin{array}{l}\text { For scattering profile, see Extended } \\
\text { Data Figure } 1\end{array}$ & Mobley \& Sundman ${ }^{19}$ \\
\hline Phase function & - & $\mathrm{sr}^{-1}$ & See reference & Table 3.10 in Mobley ${ }^{11}$ \\
\hline \multicolumn{5}{|c|}{ Sea-surface boundary model } \\
\hline wind speed & 5 & $\mathrm{~m} / \mathrm{s}$ & & \\
\hline $\begin{array}{l}\text { Real index of refraction of } \\
\text { water }\end{array}$ & 1.34 & - & Wavelength independent & \\
\hline \multicolumn{5}{|c|}{ Atmospheric model (RADTRAN-X) } \\
\hline Solar zenith angle & 30 & degrees & - & - \\
\hline Cloud cover & 0 & percent & Clear sky & \\
\hline Earth-sun distance & & & Yearly average & \\
\hline 24-h averaged wind speed & 5 & $\mathrm{~m} / \mathrm{s}$ & & \\
\hline Horizontal visibility & 15 & $\mathrm{~km}$ & & \\
\hline Relative humidity & 80 & percent & & \\
\hline Precipitable water content & 2.5 & $\mathrm{~cm}$ & & \\
\hline Total ozone & 300 & $\begin{array}{l}\text { Dobson } \\
\text { units }\end{array}$ & Yearly average & \\
\hline Airmass type & 1 & - & Marine & \\
\hline \multicolumn{5}{|c|}{ Bottom reflection model } \\
\hline Depth & - & $\mathrm{m}$ & Infinitely deep (no bottom reflection) & \\
\hline \multicolumn{5}{|c|}{ Output } \\
\hline Wavebands & $400-700$ & $\mathrm{~nm}$ & 2-nm intervals & \\
\hline Max depth & - & $\mathrm{m}$ & Max depth is $\sim 5$ optical depths & \\
\hline Number of depth intervals & 20 & - & & \\
\hline
\end{tabular}


Supplementary Table 2: Overview of the relative abundance data collected at each station, with the name and location of each station, absorption by dissolved and detrital matter at $443 \mathrm{~nm}\left(\mathrm{a}_{\mathrm{dg}}(443)\right)$, the relative abundances of the five cyanobacterial pigment types (Prochlorococcus (Pro), PCB-, PEB-, PUB-rich Synechococcus, chromatic acclimators (CA)), the applied method and the source of the data.

\begin{tabular}{|c|c|c|c|c|c|c|c|c|c|c|c|}
\hline \multirow[t]{2}{*}{ Station } & \multicolumn{3}{|c|}{ Location } & \multirow{2}{*}{$\frac{a_{d g}(443)}{\left(m^{-1}\right)}$} & \multicolumn{5}{|c|}{ Pigment type } & \multirow[t]{2}{*}{ Method } & \multirow[t]{2}{*}{ Data source } \\
\hline & lon & lat & region & & Pro & PCB & PEB & PUB & $\mathrm{CA}$ & & \\
\hline TARA_ST004_SUR & -6.539 & 36.573 & - & - & 0.931 & 0.000 & 0.000 & 0.054 & 0.014 & metagenomics & 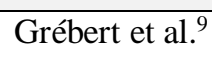 \\
\hline TARA_ST007_SUR & 1.949 & 37.021 & - & 0.0193 & 0.711 & 0.000 & 0.057 & 0.059 & 0.173 & metagenomics & Grébert et al. ${ }^{9}$ \\
\hline TARA_ST009_SUR & 5.860 & 39.073 & - & 0.0170 & 0.625 & 0.000 & 0.009 & 0.305 & 0.061 & metagenomics & Grébert et al..$^{9}$ \\
\hline TARA_ST018_SUR & 14.261 & 35.758 & - & 0.0186 & 0.992 & 0.000 & 0.000 & 0.006 & 0.003 & metagenomics & Grébert et al. ${ }^{9}$ \\
\hline TARA_ST023_SUR & 17.717 & 42.190 & - & 0.0388 & 0.584 & 0.000 & 0.056 & 0.268 & 0.091 & metagenomics & Grébert et al..$^{9}$ \\
\hline TARA_ST025_SUR & 19.391 & 39.388 & - & 0.0280 & 0.375 & 0.000 & 0.076 & 0.434 & 0.115 & metagenomics & Grébert et al. ${ }^{9}$ \\
\hline TARA_ST030_SUR & 32.860 & 33.919 & - & 0.0184 & 0.709 & 0.000 & 0.000 & 0.209 & 0.082 & metagenomics & Grébert et al. ${ }^{9}$ \\
\hline TARA_ST031_SUR & 34.818 & 27.150 & - & 0.0208 & 0.970 & 0.000 & 0.000 & 0.025 & 0.004 & metagenomics & Grébert et al. ${ }^{9}$ \\
\hline TARA_ST032_SUR & 37.216 & 23.373 & - & 0.0190 & 0.978 & 0.000 & 0.001 & 0.015 & 0.006 & metagenomics & Grébert et al. ${ }^{9}$ \\
\hline TARA_ST033_SUR & 38.217 & 22.052 & - & 0.0340 & 0.538 & 0.000 & 0.229 & 0.142 & 0.091 & metagenomics & Grébert et al. ${ }^{9}$ \\
\hline TARA_ST034_SUR & 39.869 & 18.398 & - & 0.0436 & 0.533 & 0.000 & 0.305 & 0.096 & 0.067 & metagenomics & Grébert et al. ${ }^{9}$ \\
\hline TARA_ST036_SUR & 63.505 & 20.818 & - & 0.0552 & 0.060 & 0.000 & 0.561 & 0.072 & 0.307 & metagenomics & Grébert et al. ${ }^{9}$ \\
\hline TARA_ST038_SUR & 64.494 & 19.039 & - & 0.0705 & 0.596 & 0.000 & 0.191 & 0.085 & 0.128 & metagenomics & Grébert et al. ${ }^{9}$ \\
\hline TARA_ST041_SUR & 69.981 & 14.595 & - & 0.0151 & 0.980 & 0.000 & 0.003 & 0.015 & 0.002 & metagenomics & Grébert et al. ${ }^{9}$ \\
\hline TARA_ST042_SUR & 73.894 & 6.031 & - & 0.0090 & 0.995 & 0.000 & 0.000 & 0.005 & 0.000 & metagenomics & Grébert et al. ${ }^{9}$ \\
\hline TARA_ST045_SUR & 71.644 & 0.005 & - & 0.0049 & 0.991 & 0.000 & 0.000 & 0.009 & 0.000 & metagenomics & Grébert et al. ${ }^{9}$ \\
\hline TARA_ST052_SUR & 53.996 & -16.955 & - & 0.0089 & 0.988 & 0.000 & 0.000 & 0.012 & 0.000 & metagenomics & Grébert et al. ${ }^{9}$ \\
\hline TARA_ST056_SUR & 43.295 & -15.338 & - & 0.0123 & 0.989 & 0.000 & 0.000 & 0.008 & 0.002 & metagenomics & Grébert et al. ${ }^{9}$ \\
\hline TARA_ST057_SUR & 42.833 & -16.092 & - & 0.0131 & 0.741 & 0.000 & 0.039 & 0.100 & 0.120 & metagenomics & Grébert et al. ${ }^{9}$ \\
\hline TARA_ST062_SUR & 40.204 & -22.193 & - & 0.0146 & 0.926 & 0.000 & 0.002 & 0.038 & 0.033 & metagenomics & Grébert et al..$^{9}$ \\
\hline TARA_ST064_SUR & 37.990 & -29.502 & - & 0.0236 & 0.949 & 0.000 & 0.002 & 0.001 & 0.048 & metagenomics & Grébert et al..$^{9}$ \\
\hline TARA_ST065_SUR & 26.289 & -35.189 & - & 0.0328 & 0.661 & 0.000 & 0.031 & 0.089 & 0.219 & metagenomics & Grébert et al. ${ }^{9}$ \\
\hline
\end{tabular}




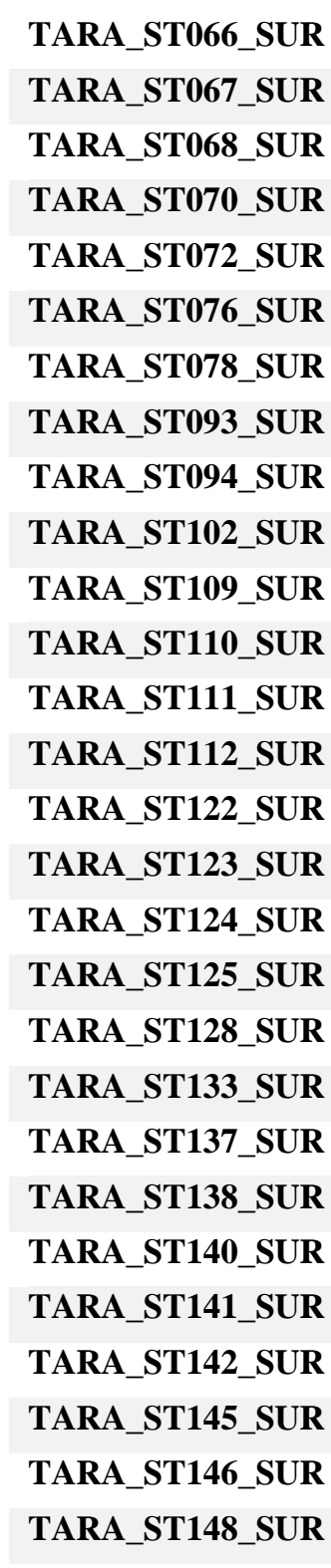

\begin{tabular}{|c|c|c|c|c|c|c|c|c|}
\hline 17.937 & -34.936 & - & 0.0436 & 0.833 & 0.000 & 0.000 & 0.000 & 0.167 \\
\hline 17.708 & -32.232 & - & - & 0.000 & 0.000 & 0.879 & 0.080 & 0.042 \\
\hline 4.688 & -31.030 & - & 0.0178 & 0.804 & 0.000 & 0.001 & 0.059 & 0.137 \\
\hline-3.186 & -20.437 & - & 0.0080 & 0.953 & 0.000 & 0.001 & 0.018 & 0.028 \\
\hline-17.913 & -8.776 & - & 0.0117 & 0.990 & 0.000 & 0.000 & 0.010 & 0.000 \\
\hline-35.196 & -20.941 & - & 0.0053 & 0.969 & 0.000 & 0.000 & 0.030 & 0.001 \\
\hline-43.290 & -30.138 & - & 0.0090 & 0.948 & 0.000 & 0.001 & 0.031 & 0.020 \\
\hline-73.084 & -34.049 & - & 0.0576 & 0.146 & 0.000 & 0.002 & 0.143 & 0.709 \\
\hline-87.085 & -32.785 & - & 0.0095 & 0.935 & 0.000 & 0.001 & 0.062 & 0.002 \\
\hline-85.161 & -5.252 & - & 0.0178 & 0.867 & 0.000 & 0.070 & 0.021 & 0.042 \\
\hline-84.573 & 2.018 & - & 0.0104 & 0.834 & 0.000 & 0.118 & 0.035 & 0.012 \\
\hline-84.590 & -2.009 & - & 0.0352 & 0.923 & 0.000 & 0.009 & 0.039 & 0.029 \\
\hline-100.672 & -16.958 & - & 0.0081 & 0.992 & 0.000 & 0.000 & 0.008 & 0.000 \\
\hline-129.395 & -23.281 & - & 0.0033 & 0.998 & 0.000 & 0.000 & 0.002 & 0.001 \\
\hline-139.213 & -8.990 & - & 0.0088 & 0.991 & 0.000 & 0.000 & 0.009 & 0.000 \\
\hline-140.284 & -8.907 & - & 0.0137 & 0.226 & 0.000 & 0.018 & 0.749 & 0.008 \\
\hline-140.576 & -9.110 & - & 0.0160 & 0.630 & 0.000 & 0.005 & 0.359 & 0.006 \\
\hline-142.557 & -8.911 & - & 0.0106 & 0.837 & 0.000 & 0.000 & 0.159 & 0.004 \\
\hline-153.679 & 0.000 & - & 0.0129 & 0.971 & 0.000 & 0.000 & 0.029 & 0.000 \\
\hline-127.743 & 35.407 & - & 0.0219 & 0.889 & 0.000 & 0.007 & 0.051 & 0.053 \\
\hline-116.629 & 14.202 & - & 0.0138 & 0.938 & 0.000 & 0.029 & 0.024 & 0.009 \\
\hline-102.943 & 6.333 & - & 0.0085 & 0.995 & 0.000 & 0.000 & 0.004 & 0.000 \\
\hline-79.303 & 7.412 & - & 0.0348 & 0.686 & 0.000 & 0.260 & 0.001 & 0.053 \\
\hline-80.061 & 9.843 & - & 0.0313 & 0.215 & 0.001 & 0.645 & 0.065 & 0.075 \\
\hline-88.383 & 25.510 & - & 0.0158 & 0.784 & 0.000 & 0.001 & 0.140 & 0.075 \\
\hline-70.033 & 39.230 & - & 0.0435 & 0.010 & 0.000 & 0.026 & 0.053 & 0.911 \\
\hline-71.302 & 34.678 & - & 0.0143 & 0.572 & 0.000 & 0.023 & 0.026 & 0.379 \\
\hline-64.180 & 31.764 & - & 0.0185 & 0.518 & 0.000 & 0.023 & 0.054 & 0.405 \\
\hline
\end{tabular}

metagenomics metagenomics metagenomics metagenomics metagenomics metagenomics metagenomics metagenomics metagenomics metagenomics metagenomics metagenomics metagenomics metagenomics metagenomics metagenomics metagenomics metagenomics metagenomics metagenomics metagenomics metagenomics metagenomics metagenomics metagenomics metagenomics metagenomics metagenomics
Grébert et al. ${ }^{9}$

Grébert et al. ${ }^{9}$

Grébert et al. ${ }^{9}$

Grébert et al. ${ }^{9}$

Grébert et al. ${ }^{9}$

Grébert et al. ${ }^{9}$

Grébert et al. ${ }^{9}$

Grébert et al. ${ }^{9}$

Grébert et al. ${ }^{9}$

Grébert et al. ${ }^{9}$

Grébert et al. ${ }^{9}$

Grébert et al. ${ }^{9}$

Grébert et al. ${ }^{9}$

Grébert et al. ${ }^{9}$

Grébert et al. ${ }^{9}$

Grébert et al. ${ }^{9}$

Grébert et al. ${ }^{9}$

Grébert et al. ${ }^{9}$

Grébert et al. ${ }^{9}$

Grébert et al. ${ }^{9}$

Grébert et al. ${ }^{9}$

Grébert et al. ${ }^{9}$

Grébert et al. ${ }^{9}$

Grébert et al. ${ }^{9}$

Grébert et al. ${ }^{9}$

Grébert et al. ${ }^{9}$

Grébert et al. ${ }^{9}$

Grébert et al. ${ }^{9}$ 


\begin{tabular}{|c|c|c|c|c|c|c|c|c|c|c|c|}
\hline TARA_ST149_SUR & -49.891 & 34.096 & - & 0.0194 & 0.370 & 0.001 & 0.013 & 0.018 & 0.599 & metagenomics & Grébert et al. ${ }^{9}$ \\
\hline TARA_ST150_SUR & -37.261 & 35.907 & - & 0.0198 & 0.910 & 0.000 & 0.000 & 0.021 & 0.069 & metagenomics & Grébert et al. ${ }^{9}$ \\
\hline TARA_ST151_SUR & -29.009 & 36.156 & - & 0.0166 & 0.922 & 0.000 & 0.000 & 0.033 & 0.045 & metagenomics & Grébert et al. ${ }^{9}$ \\
\hline TARA_ST152_SUR & -16.852 & 43.688 & - & 0.0238 & 0.737 & 0.000 & 0.000 & 0.076 & 0.187 & metagenomics & Grébert et al..$^{9}$ \\
\hline L. Balaton (Fuzfo Basin) & 17.730 & 46.830 & Hungary & 3.3127 & 0.000 & 0.270 & 0.730 & 0.000 & 0.000 & $\begin{array}{l}\text { epifluorescence } \\
\text { microscopy }\end{array}$ & Vörös et al. ${ }^{6}$ \\
\hline L. Balaton (Tihany basin) & 17.740 & 46.840 & Hungary & 5.4811 & 0.000 & 0.430 & 0.570 & 0.000 & 0.000 & $\begin{array}{l}\text { epifluorescence } \\
\text { microscopy }\end{array}$ & Vörös et al. ${ }^{6}$ \\
\hline L. Balaton (Zanka basin) & 17.750 & 46.850 & Hungary & 3.8950 & 0.000 & 0.370 & 0.630 & 0.000 & 0.000 & $\begin{array}{l}\text { epifluorescence } \\
\text { microscopy }\end{array}$ & Vörös et al. ${ }^{6}$ \\
\hline L. Balaton (Szigliget basin) & 17.760 & 46.860 & Hungary & 2.9915 & 0.000 & 0.730 & 0.270 & 0.000 & 0.000 & $\begin{array}{l}\text { epifluorescence } \\
\text { microscopy }\end{array}$ & Vörös et al. ${ }^{6}$ \\
\hline L. Balaton (Keszthely basin) & 17.770 & 46.870 & Hungary & 4.3568 & 0.000 & 0.270 & 0.730 & 0.000 & 0.000 & $\begin{array}{l}\text { epifluorescence } \\
\text { microscopy }\end{array}$ & Vörös et al. ${ }^{6}$ \\
\hline L. Balaton (Zala river) & 17.780 & 46.880 & Hungary & 6.0834 & 0.000 & 0.940 & 0.060 & 0.000 & 0.000 & $\begin{array}{l}\text { epifluorescence } \\
\text { microscopy }\end{array}$ & Vörös et al. ${ }^{6}$ \\
\hline Kis-Balaton (upper res.) & 17.140 & 46.640 & Hungary & 7.6695 & 0.000 & 1.000 & 0.000 & 0.000 & 0.000 & $\begin{array}{l}\text { epifluorescence } \\
\text { microscopy }\end{array}$ & Vörös et al. ${ }^{6}$ \\
\hline Kis-Balaton (lower res.) & 17.150 & 46.650 & Hungary & 9.3560 & 0.000 & 1.000 & 0.000 & 0.000 & 0.000 & $\begin{array}{l}\text { epifluorescence } \\
\text { microscopy }\end{array}$ & Vörös et al. ${ }^{6}$ \\
\hline Marcali reservoir & 17.440 & 46.610 & Hungary & 6.9869 & 0.000 & 1.000 & 0.000 & 0.000 & 0.000 & $\begin{array}{l}\text { epifluorescence } \\
\text { microscopy }\end{array}$ & Vörös et al. ${ }^{6}$ \\
\hline Monostorapati reservoir & 17.540 & 46.920 & Hungary & 12.046 & 0.000 & 0.960 & 0.040 & 0.000 & 0.000 & $\begin{array}{l}\text { epifluorescence } \\
\text { microscopy }\end{array}$ & Vörös et al. ${ }^{6}$ \\
\hline L. Pecsi & 18.140 & 46.160 & Hungary & 2.8309 & 0.000 & 0.220 & 0.780 & 0.000 & 0.000 & $\begin{array}{l}\text { epifluorescence } \\
\text { microscopy }\end{array}$ & Vörös et al. ${ }^{6}$ \\
\hline L. Herman Otto & 18.130 & 46.170 & Hungary & 7.9305 & 0.000 & 0.680 & 0.320 & 0.000 & 0.000 & $\begin{array}{l}\text { epifluorescence } \\
\text { microscopy }\end{array}$ & Vörös et al. ${ }^{6}$ \\
\hline L. Como & 9.260 & 46.020 & Italy & 0.5622 & 0.000 & 0.020 & 0.980 & 0.000 & 0.000 & $\begin{array}{l}\text { epifluorescence } \\
\text { microscopy }\end{array}$ & Vörös et al. ${ }^{6}$ \\
\hline L. Maggiore & 8.650 & 46.000 & Italy & 0.8633 & 0.000 & 0.040 & 0.960 & 0.000 & 0.000 & $\begin{array}{l}\text { epifluorescence } \\
\text { microscopy }\end{array}$ & Vörös et al. ${ }^{6}$ \\
\hline L. Garda & 10.640 & 45.600 & Italy & 0.4417 & 0.000 & 0.020 & 0.980 & 0.000 & 0.000 & $\begin{array}{l}\text { epifluorescence } \\
\text { microscopy }\end{array}$ & Vörös et al. ${ }^{6}$ \\
\hline L. Iseo & 10.070 & 45.720 & Italy & 0.5822 & 0.000 & 0.010 & 0.990 & 0.000 & 0.000 & $\begin{array}{l}\text { epifluorescence } \\
\text { microscopy }\end{array}$ & Vörös et al. ${ }^{6}$ \\
\hline
\end{tabular}




\begin{tabular}{|c|c|c|c|c|c|c|c|c|c|c|c|}
\hline L. Orta & 8.400 & 45.810 & Italy & 0.9236 & 0.000 & 0.000 & 1.000 & 0.000 & 0.000 & $\begin{array}{l}\text { epifluorescence } \\
\text { microscopy }\end{array}$ & Vörös et al. ${ }^{6}$ \\
\hline L. Mergozzo & 8.470 & 46.000 & Italy & 0.5019 & 0.000 & 0.010 & 0.990 & 0.000 & 0.000 & $\begin{array}{l}\text { epifluorescence } \\
\text { microscopy }\end{array}$ & Vörös et al. ${ }^{6}$ \\
\hline L. Varese & 8.740 & 45.810 & Italy & 1.3853 & 0.000 & 0.460 & 0.540 & 0.000 & 0.000 & $\begin{array}{l}\text { epifluorescence } \\
\text { microscopy }\end{array}$ & Vörös et al. ${ }^{6}$ \\
\hline L. Candia & 7.910 & 45.320 & Italy & 0.9838 & 0.000 & 0.500 & 0.500 & 0.000 & 0.000 & $\begin{array}{l}\text { epifluorescence } \\
\text { microscopy }\end{array}$ & Vörös et al. ${ }^{6}$ \\
\hline L. Paione Superiore & 8.190 & 46.180 & Italy & 0.7027 & 0.000 & 0.000 & 1.000 & 0.000 & 0.000 & $\begin{array}{l}\text { epifluorescence } \\
\text { microscopy }\end{array}$ & Vörös et al. ${ }^{6}$ \\
\hline L. Paione Inferiore & 8.190 & 46.170 & Italy & 0.2409 & 0.000 & 0.000 & 1.000 & 0.000 & 0.000 & $\begin{array}{l}\text { epifluorescence } \\
\text { microscopy }\end{array}$ & Vörös et al. ${ }^{6}$ \\
\hline L. Azzuro & - & - & Italy & 0.6023 & 0.000 & 0.000 & 1.000 & 0.000 & 0.000 & $\begin{array}{l}\text { epifluorescence } \\
\text { microscopy }\end{array}$ & Vörös et al. ${ }^{6}$ \\
\hline L. Devero & 8.290 & 46.340 & Italy & 0.7027 & 0.000 & 0.000 & 1.000 & 0.000 & 0.000 & $\begin{array}{l}\text { epifluorescence } \\
\text { microscopy }\end{array}$ & Vörös et al. ${ }^{6}$ \\
\hline L. Piramide Superiore & 86.480 & 27.570 & Nepal & 0.4216 & 0.000 & 0.000 & 1.000 & 0.000 & 0.000 & $\begin{array}{l}\text { epifluorescence } \\
\text { microscopy }\end{array}$ & Vörös et al. ${ }^{6}$ \\
\hline L. Piramide Inferiore & 86.480 & 27.570 & Nepal & 0.2409 & 0.000 & 0.000 & 1.000 & 0.000 & 0.000 & $\begin{array}{l}\text { epifluorescence } \\
\text { microscopy }\end{array}$ & Vörös et al. ${ }^{6}$ \\
\hline Okareka & 176.360 & -38.170 & New Zealand & 0.6023 & 0.000 & 0.450 & 0.550 & 0.000 & 0.000 & $\begin{array}{l}\text { epifluorescence } \\
\text { microscopy }\end{array}$ & Pick et al. ${ }^{5}$ \\
\hline Tarawera & 176.430 & -38.190 & New Zealand & 0.7228 & 0.000 & 0.000 & 1.000 & 0.000 & 0.000 & $\begin{array}{l}\text { epifluorescence } \\
\text { microscopy }\end{array}$ & Pick et al. ${ }^{5}$ \\
\hline Rotorua & 176.270 & -38.080 & New Zealand & 1.6062 & 0.000 & 0.400 & 0.600 & 0.000 & 0.000 & $\begin{array}{l}\text { epifluorescence } \\
\text { microscopy }\end{array}$ & Pick et al. ${ }^{5}$ \\
\hline Superior & -86.790 & 48.160 & Ontario & 0.3815 & 0.000 & 0.000 & 1.000 & 0.000 & 0.000 & $\begin{array}{l}\text { epifluorescence } \\
\text { microscopy }\end{array}$ & Pick et al. ${ }^{5}$ \\
\hline Erie (east) & -81.270 & 42.420 & Ontario & 0.8432 & 0.000 & 0.000 & 1.000 & 0.000 & 0.000 & $\begin{array}{l}\text { epifluorescence } \\
\text { microscopy }\end{array}$ & Pick et al. ${ }^{5}$ \\
\hline Erie (central) & -81.270 & 42.420 & Ontario & 0.6425 & 0.000 & 0.000 & 1.000 & 0.000 & 0.000 & $\begin{array}{l}\text { epifluorescence } \\
\text { microscopy }\end{array}$ & Pick et al..$^{5}$ \\
\hline Erie (west) & -81.270 & 42.420 & Ontario & 1.8873 & 0.000 & 0.330 & 0.670 & 0.000 & 0.000 & $\begin{array}{l}\text { epifluorescence } \\
\text { microscopy }\end{array}$ & Pick et al. ${ }^{5}$ \\
\hline Ontario & -77.900 & 43.850 & Ontario & 0.8232 & 0.000 & 0.000 & 1.000 & 0.000 & 0.000 & $\begin{array}{l}\text { epifluorescence } \\
\text { microscopy }\end{array}$ & Pick et al..$^{5}$ \\
\hline Bay of Quinte & -77.210 & 44.150 & Ontario & 4.3166 & 0.000 & 0.890 & 0.110 & 0.000 & 0.000 & $\begin{array}{l}\text { epifluorescence } \\
\text { microscopy }\end{array}$ & Pick et al..$^{5}$ \\
\hline
\end{tabular}




\begin{tabular}{|c|c|c|c|c|c|c|c|c|c|c|c|}
\hline Cherry & -80.460 & 48.450 & Ontario & 1.6664 & 0.000 & 0.840 & 0.160 & 0.000 & 0.000 & $\begin{array}{l}\text { epifluorescence } \\
\text { microscopy }\end{array}$ & Pick et al. ${ }^{5}$ \\
\hline Triangle & -93.570 & 49.840 & Ontario & 1.1846 & 0.000 & 0.510 & 0.490 & 0.000 & 0.000 & $\begin{array}{l}\text { epifluorescence } \\
\text { microscopy }\end{array}$ & Pick et al. ${ }^{5}$ \\
\hline Bay & -79.210 & 45.510 & Ontario & 0.7027 & 0.000 & 0.000 & 1.000 & 0.000 & 0.000 & $\begin{array}{l}\text { epifluorescence } \\
\text { microscopy }\end{array}$ & Pick et al. ${ }^{5}$ \\
\hline Buller & -93.210 & 49.980 & Ontario & 0.9236 & 0.000 & 0.000 & 1.000 & 0.000 & 0.000 & $\begin{array}{l}\text { epifluorescence } \\
\text { microscopy }\end{array}$ & Pick et al. ${ }^{5}$ \\
\hline Halls & -78.750 & 45.110 & Ontario & 0.4819 & 0.000 & 0.120 & 0.880 & 0.000 & 0.000 & $\begin{array}{l}\text { epifluorescence } \\
\text { microscopy }\end{array}$ & Pick et al..$^{5}$ \\
\hline Koshlong & -78.480 & 44.970 & Ontario & 0.9637 & 0.000 & 0.320 & 0.680 & 0.000 & 0.000 & $\begin{array}{l}\text { epifluorescence } \\
\text { microscopy }\end{array}$ & Pick et al..$^{5}$ \\
\hline Anstruther & -78.230 & 44.740 & Ontario & 1.3853 & 0.000 & 0.810 & 0.190 & 0.000 & 0.000 & $\begin{array}{l}\text { epifluorescence } \\
\text { microscopy }\end{array}$ & Pick et al. ${ }^{5}$ \\
\hline L Amable & -77.820 & 45.020 & Ontario & 0.9637 & 0.000 & 0.000 & 1.000 & 0.000 & 0.000 & $\begin{array}{l}\text { epifluorescence } \\
\text { microscopy }\end{array}$ & Pick et al. \\
\hline Opeongo & -78.400 & 45.730 & Ontario & 2.4293 & 0.000 & 0.790 & 0.210 & 0.000 & 0.000 & $\begin{array}{l}\text { epifluorescence } \\
\text { microscopy }\end{array}$ & Pick et al..$^{5}$ \\
\hline St. Nora & -78.830 & 45.160 & Ontario & 1.8270 & 0.000 & 0.480 & 0.520 & 0.000 & 0.000 & $\begin{array}{l}\text { epifluorescence } \\
\text { microscopy }\end{array}$ & Pick et al. \\
\hline Crawford & -79.950 & 43.470 & Ontario & 0.9035 & 0.000 & 0.000 & 1.000 & 0.000 & 0.000 & $\begin{array}{l}\text { epifluorescence } \\
\text { microscopy }\end{array}$ & Pick et al. ${ }^{5}$ \\
\hline Drag & -78.410 & 45.070 & Ontario & 0.9637 & 0.000 & 0.080 & 0.920 & 0.000 & 0.000 & $\begin{array}{l}\text { epifluorescence } \\
\text { microscopy }\end{array}$ & Pick et al..$^{5}$ \\
\hline Wolf & -80.630 & 46.850 & Ontario & 1.7266 & 0.000 & 0.650 & 0.350 & 0.000 & 0.000 & $\begin{array}{l}\text { epifluorescence } \\
\text { microscopy }\end{array}$ & Pick et al. ${ }^{5}$ \\
\hline Picard & -78.390 & 44.780 & Ontario & 0.9637 & 0.000 & 0.010 & 0.990 & 0.000 & 0.000 & $\begin{array}{l}\text { epifluorescence } \\
\text { microscopy }\end{array}$ & Pick et al. \\
\hline Salmon & -78.440 & 44.820 & Ontario & 0.7027 & 0.000 & 0.000 & 1.000 & 0.000 & 0.000 & $\begin{array}{l}\text { epifluorescence } \\
\text { microscopy }\end{array}$ & Pick et al..$^{5}$ \\
\hline Bobs GB & -76.590 & 44.700 & Ontario & 0.8232 & 0.000 & 0.070 & 0.930 & 0.000 & 0.000 & $\begin{array}{l}\text { epifluorescence } \\
\text { microscopy }\end{array}$ & Pick et al. \\
\hline Chub & -79.230 & 45.300 & Ontario & 1.7066 & 0.000 & 1.000 & 0.000 & 0.000 & 0.000 & $\begin{array}{l}\text { epifluorescence } \\
\text { microscopy }\end{array}$ & Pick et al. \\
\hline Jacks & -78.050 & 44.690 & Ontario & 1.1444 & 0.000 & 0.050 & 0.950 & 0.000 & 0.000 & $\begin{array}{l}\text { epifluorescence } \\
\text { microscopy }\end{array}$ & Pick et al. \\
\hline Bobs WB & -76.560 & 44.700 & Ontario & 1.4857 & 0.000 & 0.340 & 0.660 & 0.000 & 0.000 & $\begin{array}{l}\text { epifluorescence } \\
\text { microscopy }\end{array}$ & Pick et al. ${ }^{5}$ \\
\hline
\end{tabular}




\begin{tabular}{|c|c|c|c|c|c|c|c|c|c|c|c|}
\hline St. George & -79.430 & 43.960 & Ontario & 1.3251 & 0.000 & 0.470 & 0.530 & 0.000 & 0.000 & $\begin{array}{l}\text { epifluorescence } \\
\text { microscopy }\end{array}$ & Pick et al. ${ }^{5}$ \\
\hline Rice & -78.180 & 44.180 & Ontario & 3.0517 & 0.000 & 0.820 & 0.180 & 0.000 & 0.000 & $\begin{array}{l}\text { epifluorescence } \\
\text { microscopy }\end{array}$ & Pick et al. ${ }^{5}$ \\
\hline Heart & -79.800 & 43.740 & Ontario & 4.6981 & 0.000 & 1.000 & 0.000 & 0.000 & 0.000 & $\begin{array}{l}\text { epifluorescence } \\
\text { microscopy }\end{array}$ & Pick et al. ${ }^{5}$ \\
\hline Island & -113.540 & 54.840 & Alberta & 1.5259 & 0.000 & 0.100 & 0.900 & 0.000 & 0.000 & $\begin{array}{l}\text { epifluorescence } \\
\text { microscopy }\end{array}$ & Pick et al. ${ }^{5}$ \\
\hline Amisk & -112.640 & 54.600 & Alberta & 2.2286 & 0.000 & 0.090 & 0.910 & 0.000 & 0.000 & $\begin{array}{l}\text { epifluorescence } \\
\text { microscopy }\end{array}$ & Pick et al. ${ }^{5}$ \\
\hline LL3A & 26.210 & 60.040 & Baltic Sea & 1.7266 & 0.000 & 0.450 & 0.550 & 0.000 & 0.000 & flow cytometry & Stomp et al. ${ }^{7}$ \\
\hline CYA04_2 & 19.860 & 58.490 & Baltic Sea & 0.6224 & 0.000 & 0.230 & 0.770 & 0.000 & 0.000 & flow cytometry & Stomp et al. ${ }^{7}$ \\
\hline CYA04_3 & 19.860 & 58.490 & Baltic Sea & 1.4054 & 0.000 & 0.310 & 0.690 & 0.000 & 0.000 & flow cytometry & Stomp et al. ${ }^{7}$ \\
\hline CYA04_7 & 19.860 & 58.490 & Baltic Sea & 1.2649 & 0.000 & 0.280 & 0.720 & 0.000 & 0.000 & flow cytometry & Stomp et al. ${ }^{7}$ \\
\hline CYA04_11 & 19.860 & 58.490 & Baltic Sea & 2.3490 & 0.000 & 0.610 & 0.390 & 0.000 & 0.000 & flow cytometry & Stomp et al. ${ }^{7}$ \\
\hline CYA04_15 & 19.860 & 58.490 & Baltic Sea & 1.3452 & 0.000 & 0.340 & 0.660 & 0.000 & 0.000 & flow cytometry & Stomp et al. ${ }^{7}$ \\
\hline CYA04_20 & 19.860 & 58.490 & Baltic Sea & 1.1243 & 0.000 & 0.490 & 0.510 & 0.000 & 0.000 & flow cytometry & Stomp et al. ${ }^{7}$ \\
\hline CYA04_22 & 19.860 & 58.490 & Baltic Sea & 1.4255 & 0.000 & 0.480 & 0.520 & 0.000 & 0.000 & flow cytometry & Stomp et al. ${ }^{7}$ \\
\hline CYA04_28 & 19.860 & 58.490 & Baltic Sea & 1.0440 & 0.000 & 0.350 & 0.650 & 0.000 & 0.000 & flow cytometry & Stomp et al. ${ }^{7}$ \\
\hline
\end{tabular}

